SCIREA Journal of Energy

http://www.scirea.org/journal/Energy

October 24, 2021

Volume 6, Issue 5, October 2021

\title{
Experimental Study of Polymer Injection Performance on Oil Recovery Factor Enhancement in Homogeneous and Heterogeneous Porous Media Using Acrylic Micromodel
}

\author{
Boni Swadesi $^{1 *}$, Dedy Kristanto ${ }^{1}$, Indah Widyaningsih ${ }^{1}$, Sri Wahyuni Murni ${ }^{2}$, Sinosa \\ Husenido $^{1}$, Mahruri Sanmurjana ${ }^{3}$, Roiduz Zumar ${ }^{1}$ and Septoratno Siregar ${ }^{3}$ \\ ${ }^{1}$ Department of Petroleum Engineering, Universitas Pembangunan Nasional "Veteran" \\ Yogyakarta, \\ ${ }^{2}$ Department of Chemical Engineering, Universitas Pembangunan Nasional "Veteran" \\ Yogyakarta, \\ ${ }^{3}$ Department of Petroleum Engineering, Institut Teknologi Bandung \\ Corresponding Author: Boni Swadesi; Email: boniswadesi@upnyk.ac.id
}

\begin{abstract}
:
Understanding polymer flow behaviour in porous media is essential to know the performance of polymer injection on oil recovery factor enhancement that is affected by various parameters. This research work conducted a series of waterflooding and polymer injection processes on acrylic or polymethyl methacrylate (PMMA) micromodel with homogeneous and heterogeneous flow patterns. In this study, we used the dry etching method to fabricate the micromodel. The waterflooding process is conducted first and then followed by polymer injection with different concentrations in each micromodel. The incremental oil recovery factor resulting from polymer injection can be determined and analysed to know the effect of
\end{abstract}


polymer concentration and reservoir heterogeneity on the incremental oil recovery factor. In a particular scenario, the test is conducted with different injection flow rates to understand the effect of flow rate on the oil recovery. The micromodel flooding test result is further analysed by using Digital Image Analysis (DIA). The results revealed that the highest incremental oil recovery factor is obtained when the layers are perpendicular to the mean flow direction if the polymer solution is injected from a low permeable zone. In addition, the increase of polymer concentration will result in higher incremental oil recovery and a lower injection flow rate will give better sweep efficiency. This study shows the application of micromodel for the understanding of enhanced oil recovery techniques at pore scale.

Keywords: Micromodel, Polymer Injection, Incremental Oil Recovery Factor, Digital Image Analysis.

\section{Introduction}

Waterflooding was already known as the dominant secondary recovery method among other fluid injection techniques and is widely used in the petroleum industry. Craig (1971) stated that the popularity of waterflooding implementation is due to some reasons such as the water availability, relatively more simple and easier compared to other injection techniques, the spreadability of water flow through an oil-bearing, and water's efficiency in displacing oil. Besides that, in the waterflooding process could happen viscous fingering resulting in poor sweep efficiency [1].

Polymer Injection is the most commonly applied chemical enhanced oil recovery technique to overcome viscous fingering problem that happens in waterflooding [2]. Polymer is a large molecule (macromolecule) composed of many repeated subunits called monomers [3]. The two main types of polymers are synthetic polymers such as hydrolyzed polyacrylamide (HPAM) and biopolymers such as xanthan gum. Less commonly used are natural polymers and their derivatives, such as guar gum, hydroxyl ethyl cellulose (HEC) and sodium carboxymethyl cellulose [4]. Hydrolyzed polyacrylamide (HPAM) is the most widely used polymer in EOR applications [5]. However, different characteristics of each polymer type provide their own advantages and drawbacks in which related to polymer stability due to various polymer degradations. The most significant and obvious mechanism of polymer 
injection is the increased sweep efficiency by various ways such as through the effects of polymers on fractional flow, reducing viscous fingering, improving the water-injection profile because of crossflow between vertical heterogeneous layers or areal channel sands, reducing the relative permeability of water flow (krw) more than the permeability of oil flow (kro) through disproportionate permeability reduction, and by diverting injected water from zones that have been swept [4,6,7]. According to Siginer and Bakhtiyarov (2001) in polymeric solution, flow resistance depends on the flow direction. Their experimental data shows that energy loss is high if the polymeric solution flows through the medium with the smaller permeability rather than through the section of the flow cell with the larger permeability first [8]. Flow resistance also shows a strong dependence on the concentration when the flow direction is reversed. Therefore, the implementation of polymer injection in a field-scale needs preliminary experimental study to know the performance of polymer injection in improving oil recovery at a laboratory-scale.

Coreflooding is a method that is commonly used in an experimental study to analyze the performance of polymer injection, in which the core could represent the real condition of a reservoir. But compared to the micromodel flooding method, the use of micromodel could give the visualization of oil displacement mechanism and facilitating a more detailed process description while coreflooding couldn't provide it.

Previous researchers have done some experimental studies on polymer injection using micromodels. Chatenever, A. and J.C. Calhoun, Jr. (1952) studied the fluid flow behaviour in porous media by using a micromodel. Chatenever, A. and J.C. Calhoun, Jr. were the first researchers who tried to promote the application of micromodel to understand flow behaviour in porous media [9]. Mattax, C.C. and J.R. Kyte (1961) used an etched glass micromodel to examine the effect of wettability on fluid distribution and the impact of permeability on the oil displacement mechanism. Mattax, C.C. and J.R. Kyte were the first researchers who implemented etching method in the fabrication of micromodel, where hydrofluoric acid was used to make pore structure as the flow network [10]. Emami et al. (2008) used five-spot glass type micromodel with homogeneous and heterogeneous flow patterns to know the impact of local heterogeneity and global heterogeneity on oil recovery. Based on the experimental result, the highest oil recovery was obtained if the layers are perpendicular to the mean flow direction $\left(90^{\circ}\right.$ orientation angle) [11]. Herbas et al. (2015) evaluated polymer injection process at unconsolidated sand reservoir comprehensively. The micromodel flooding result was compared with coreflooding method, where the key parameter was focus 
on recovery factor, injected pore volume at breakthrough, and residual oil saturation [12]. Sedaghat et al. (2015) conducted a study to investigate the performance of ASP flooding on heavy oil recovery using fractured five-spot micromodels. The result showed that, hydrolyzed polyacrylamide (HPAM) provides better performance among the other polymer type [13]. Shaken Kenzhekhanov (2017) studied the effect of temperature, IFT, wettability and fractured system on the oil displacement efficiency using Norland Optical Adhesive 81 (NOA81) micromodel as the porous media, where the NOA81 micromodel could be used at high temperature and the modification of wettability could be applied. Shaken Kenzhekhanov (2017) said that, although IFT was a critical parameter in oil recovery, the mobility ratio improvement could also play a crucial role in displacement efficiency from fractured porous media [14]. Hosseini et al. (2019) used glass-type micromodel to study various factors that affected on oil recovery factor such as polymer type, polymer concentration, reservoir heterogeneity and injection flow rate. The experiment was performed using homogeneous and heterogeneous micromodel with horizontal position and saturated by heavy oil which was Iranian crude oil. The experiment result showed that higher polymer concentration at low injection rate could give better sweep efficiency. Also, the swept area was dramatically influenced by heterogeneity characteristic due to the flood front movement was affected by permeability difference [15]. Sugar et al. (2020) conducted a research about the mechanism of polymer retention (adsorbtion, mechanical entrapment, and hydrodynamic retention) in porous media by using polydimethylsiloxane (PDMS) micromodel, in which soft-lithography was used to fabricate the micromodel. Fluorescent was added to the polymer solution, so that the polymer retention could be observed visually, where the data obtained during the experiment process was taken by custom-built epifluorescence microscopy setup. The setup could provide the visualization of flow mechanism at polymer molecular scale due to the use of polymer tagging and single molecule imaging technique (Sugar et al., 2020) [16].

Therefore, the understanding of various factors which affect the incremental oil recovery factor and its displacement mechanism are essential to know the polymer injection performance in purpose to avoid failures in the implementation of polymer injection at field scale. Analyzing the performance of a polymer injection in a field project requires a comprehensive knowledge not only regarding on the polymer solution's rheological behaviour, but also about the reservoir heterogeneity which affect areal sweep efficiency of the process. In addition, the injection flow rate parameter also has an important role on the optimization of polymer injection. 
In this research work, a 2D micromodel fabricated with acrylic material is used as the porous medium to study the effect of polymer concentration, reservoir heterogeneity and injection flow rate on the incremental oil recovery factor. Micromodel used in this study was designed with homogeneous and heterogeneous characteristic, so that in general it could represent flow behaviour in a reservoir due to the transparency of micromodel, the entire process of oil displacement mechanism can be directly observed and monitored by camera then the image could be further analysed by using Digital Image Analysis (DIA) to determine the oil recovery factor.

\section{Research Methodology}

The main objective of this research work was to investigate the effect of various parameters such as polymer concentration, reservoir heterogeneity and injection flow rate on incremental oil recovery. The first step was micromodel fabrication by using acrylic laser etching method. The second step was polymer rheology test and then followed by polymer aqueous stability test. The last step was micromodel flooding test which was the main experiment in this research work.

\subsection{Micromodel Fabrication}

There are three micromodels used in this research work fabricated with homogeneous and heterogeneous characteristics. The homogeneous micromodel was designed with a perfectly regular geometry model (square-shaped pore). The heterogeneous micromodels were designed with three different zones (low, medium and high permeability) and different orientation angles $\left(0^{\circ}\right.$ or parallel to the mean flow direction and $90^{\circ}$ or perpendicular to the mean flow direction). Polymethylmethacrylate (PMMA), also known as acrylic, was used as the material to fabricate all the micromodels. The design of homogeneous and heterogeneous $\left(0^{\circ}\right.$ and $90^{\circ}$ orientation angle) flow patterns is shown in Figure 1 and for the cover plate or the upper part of each micromodel is shown in Figure 2. The two parts of a micromodel, the flow pattern and the upper or cover parts, were fused by using thermal fusion bonding method. The temperature used in the thermal bonding process was $175^{\circ} \mathrm{C}$ for 45 minutes (the melting point of acrylic is $160^{\circ} \mathrm{C}$ ). The heating process was performed in order to make a completely sealed micromodel, and then the pore space would be created. Gravimetric method was used to determine the pore volume and porosity of micromodel, then the permeability of micromodel (absolute permeability) could be achieved by gathering the flow 
rate data and the pressure response. Various injection flow rates were set and then waited until the system to reach the constant (stabilized) pressure difference. By knowing the pressure difference in which the outlet pressure is assumed to equal atmospheric pressure, the absolute permeability can be calculated by Darcy's law. The characteristic of homogeneous and heterogeneous micromodel was presented in Table 1.

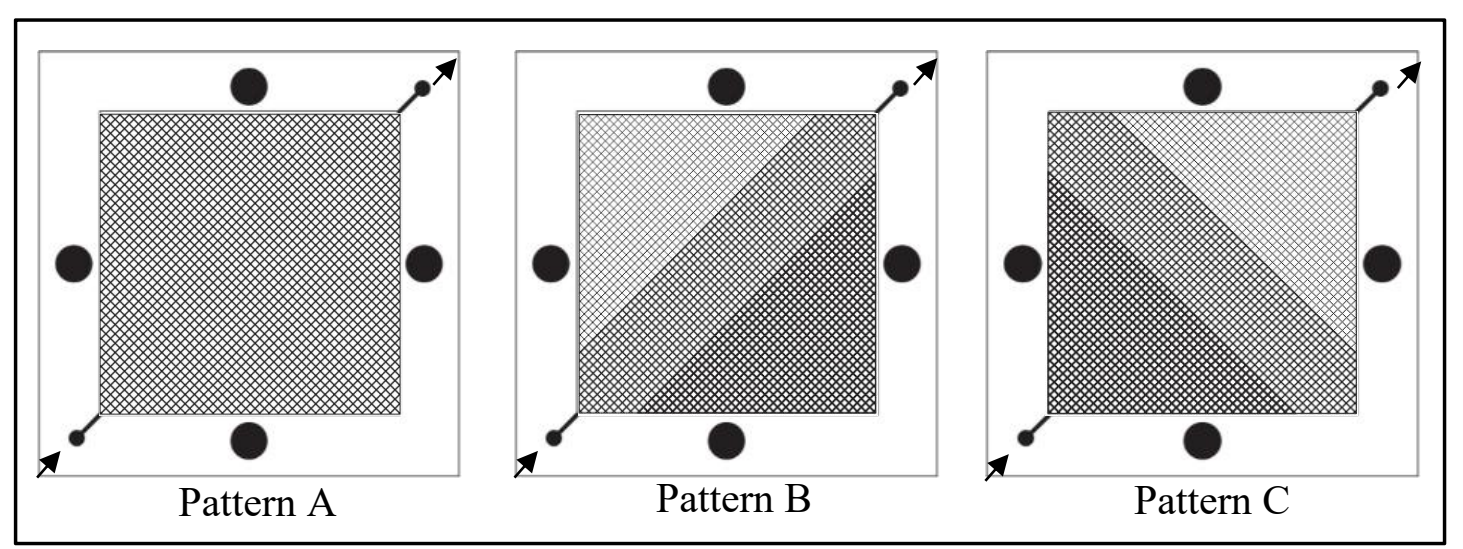

Figure 1. Micromodel Design ( $A=$ Homogeneous Micromodel, $B=$ Heterogeneous Micromodel with $0^{\circ}$ Orientation Angle or Parallel to Mean Flow Direction, $C=$ Heterogeneous Micromodel with $90^{\circ}$ Orientation Angle or Perpendicular to Mean Flow Direction)

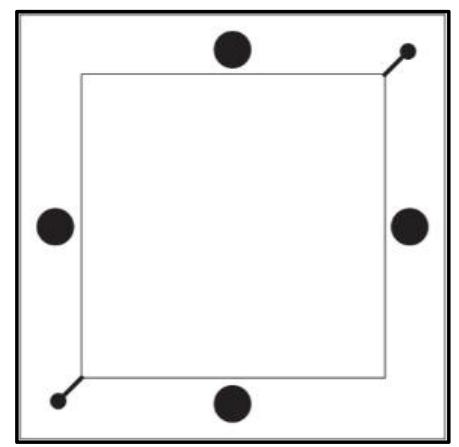

Figure 2. Cover-part Design of Micromodel

Table 1. Micromodel Characteristics

\begin{tabular}{c|ccc}
\hline \multirow{2}{*}{ Micromodel } & Homogeneous & \multicolumn{2}{c}{ Heterogeneous } \\
\cline { 2 - 4 } & A & B & C \\
\hline Length (mm) & 50 & 50 & 50 \\
Width (mm) & 50 & 50 & 50 \\
Etching Depth (mm) & 0.58 & 0.58 & 0.58 \\
Pore Size (mm) & 0.23 & 0.17 & 0.17
\end{tabular}




\begin{tabular}{|c|c|c|c|c|c|c|}
\hline & & & & 23 & & .23 \\
\hline & & & & .3 & & 0.3 \\
\hline \multicolumn{2}{|c|}{ Grain Size (mm) } & 1.1 & & 1 & & 1 \\
\hline \multicolumn{2}{|c|}{ Orientation Angle } & - & & $j^{\circ}$ & & $90^{\circ}$ \\
\hline \multicolumn{2}{|c|}{ Bulk Volume (cm $\left.{ }^{3}\right)$} & 1.45 & & 45 & & .45 \\
\hline \multicolumn{2}{|c|}{ Grain Volume $\left(\mathrm{cm}^{3}\right)$} & 0.794 & & 344 & & 844 \\
\hline \multicolumn{2}{|c|}{ Pore Volume $\left(\mathrm{cm}^{3}\right)$} & 0.656 & & 606 & & 606 \\
\hline \multicolumn{2}{|c|}{ Porosity (\%) } & 45.24 & & .79 & & 1.79 \\
\hline \multirow{3}{*}{ Absolute Permeability (D) } & Low (0.17 mm) & & & 23.48 & & 23.48 \\
\hline & Medium (0.23 mm) & 31.34 & 28.85 & 31.34 & 30.16 & 31.34 \\
\hline & High (0.3 mm) & & & 38.07 & & 38.07 \\
\hline
\end{tabular}

\subsection{Polymer Rheology Test}

Polymer rheology test was conducted to determine the polymer viscosity. The polymer product used in this research work was FP3630S which was included as HPAM (hydrolyzed polyacrylamide) polymer. The polymer viscosity was measured at various shear rates and different concentrations. In this test, Brookfield Viscometer LVDV3T was used to measure the polymer rheology properties, as shown in Figure 3. The principle of this instrument is rotational viscometry where the torque force was measured by this instrument as a result of fluid resistance (viscous drag) at various shear rates.

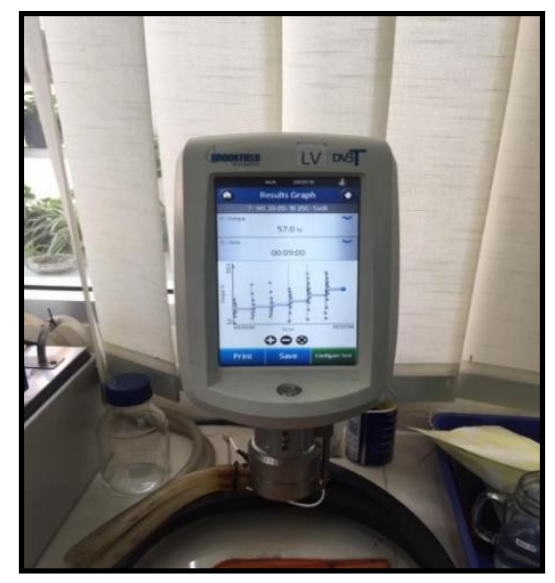

Figure 3. Brookfield Viscometer LVDV3T

\subsection{Polymer Aqueous Stability Test}

Aqueous stability test was performed to observe the polymer fluids stability at a certain range of time and temperatures. Polymer should have good stability which was indicated by no 
solid sediment formed and the polymer solution should be still in a homogeneous state during the test. The FP3630S polymer was observed in the range of concentrations $500 \mathrm{ppm}$ to 2000 ppm. The testing was conducted at $25^{\circ} \mathrm{C}$ and $60^{\circ} \mathrm{C}$ for seven days.

\subsection{Micromodel Flooding Test}

Micromodel flooding test was conducted to obtain oil recovery value resulted in every polymer injection scenario. The first step in this test was to set up the micromodel which injectivity tool and recording equipment should be prepared before the test. The injectivity tool includes a syringe pump to inject fluid into the micromodel and a connection (inlet and outlet) as the fluid flow pathway to enter and out of the micromodel. The recording equipment consists of a camera to monitor the oil displacement process during the micromodel flooding test and a light source under the micromodel to get better results of captured images during the test. The micromodel set-up is shown in Figure 4. The next step was to saturate the micromodel $100 \%$ with brine by injecting $10000 \mathrm{ppm} \mathrm{NaCl}$ synthetic brine into the micromodel to represent the wetting phase in a reservoir. After brine saturation process and then followed by oil saturation in which light oil (43.278 $\left.{ }^{\circ} \mathrm{API}\right)$ with a viscosity of $2.15 \mathrm{cp}$ (at $25^{\circ} \mathrm{C}$ ) was injected into the micromodel to represent oil migration process in the reservoir as the non-wetting phase that displaces water in the reservoir until reach a condition where water could not be displaced by oil anymore or also known as irreducible water saturation. A condition of micromodel after brine and oil saturation processes represents the initial condition before the implementation of waterflooding and polymer injection scenario. The next step was waterflooding and then followed by polymer injection. Waterflooding was performed as preliminary flooding before the implementation of polymer injection to know the incremental oil recovery resulted from every polymer injection scenario. Polymer concentrations used in this experiment were 1000 ppm, 1500 ppm and 2000 ppm. In this micromodel flooding test, there were three main scenarios namely Scenario 1: Waterflooding $+1000 \mathrm{ppm}$ polymer injection, Scenario 2: Waterflooding $+1500 \mathrm{ppm}$ polymer injection and Scenario 3: Waterflooding $+2000 \mathrm{ppm}$ polymer injection. Every polymer injection scenario was conducted in each micromodel which are homogeneous micromodel as pattern $\mathrm{A}$ and heterogeneous micromodel $\left(0^{\circ}\right.$ orientation angle as pattern $\mathrm{B}$ and $90^{\circ}$ orientation angle as pattern C). The step of micromodel flooding test is shown in Figure 5 and the detailed polymer injection scenarios are presented in Table 2. Every step of micromodel flooding test was recorded by the camera to get images of each scenario. Each type of fluids had been coloured first to be further analysed by digital image analysis. 


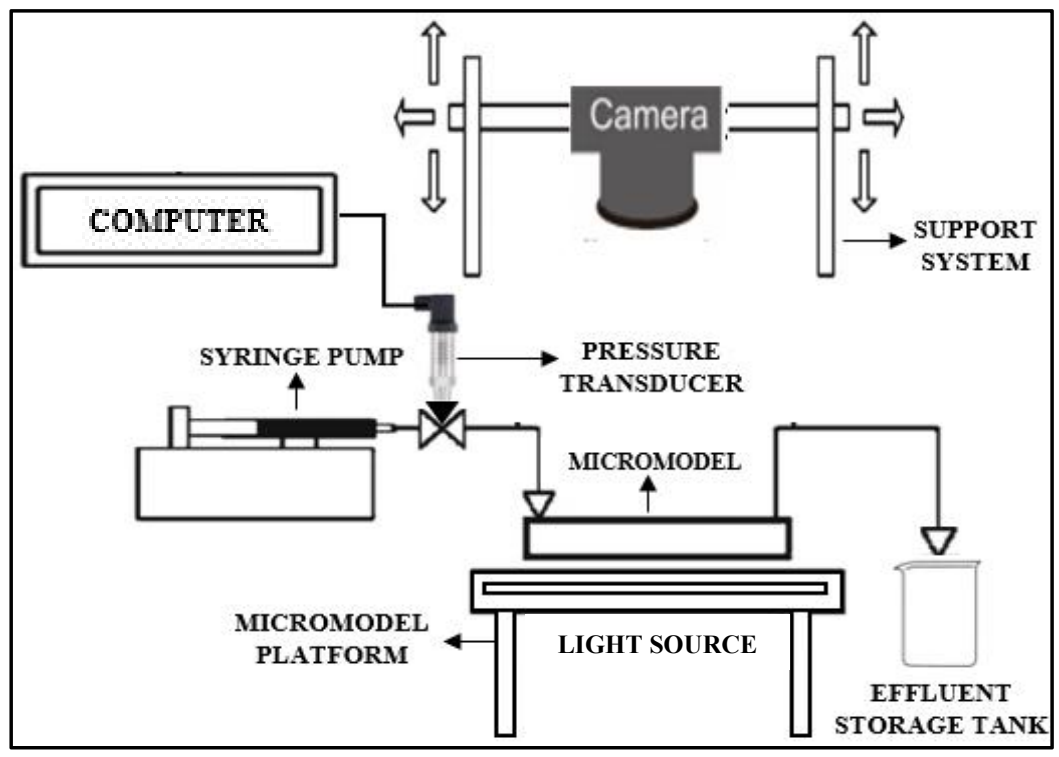

Figure 4. Scheme of Micromodel Setup

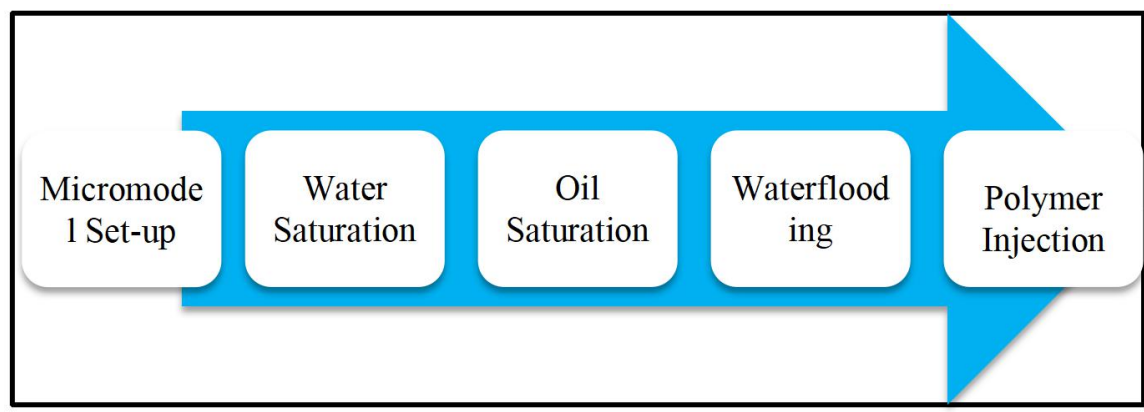

Figure 5. The Steps of Micromodel Flooding Test

Table 2. Micromodel Flooding Test Scenario

\begin{tabular}{|c|c|c|c|}
\hline Scenario & Flooding Scenario & Injection Rate & Zone \\
\hline \multicolumn{4}{|c|}{ Homogeneous Micromodel (Pattern A) } \\
\hline Scenario 1 & Waterflooding + Polymer Flooding (1000 ppm) & & \multirow{4}{*}{$\begin{array}{l}\text { Homogeneous } \\
\text { Permeability Zone }\end{array}$} \\
\hline Scenario 2 & Waterflooding + Polymer Flooding (1500 ppm) & $0.05 \mathrm{cc} / \mathrm{min}$ & \\
\hline Scenario 3 & Waterflooding + Polymer Flooding (2000 ppm) & & \\
\hline Scenario 2 & Waterflooding + Polymer Flooding (1500 ppm) & $0.08 \mathrm{cc} / \mathrm{min}$ & \\
\hline \multicolumn{4}{|c|}{ Heterogeneous Micromodel $0^{\circ}$ Orientation Angle (Pattern B) } \\
\hline Scenario 1 & Waterflooding + Polymer Flooding (1000 ppm) & \multirow{3}{*}{$0.05 \mathrm{cc} / \mathrm{min}$} & \multirow{3}{*}{$\begin{array}{l}\text { Heterogeneous } \\
\text { Permeability Zone }\end{array}$} \\
\hline Scenario 2 & Waterflooding + Polymer Flooding (1500 ppm) & & \\
\hline Scenario 3 & Waterflooding + Polymer Flooding (2000 ppm) & & \\
\hline \multicolumn{4}{|c|}{ Heterogeneous Micromodel $90^{\circ}$ Orientation Angle (Pattern C) } \\
\hline Scenario 1 & Waterflooding + Polymer Flooding (1000 ppm) & \multirow{2}{*}{$0.05 \mathrm{cc} / \mathrm{min}$} & \multirow{2}{*}{$\begin{array}{c}\text { High to Low } \\
\text { Permeability Zone }\end{array}$} \\
\hline Scenario 2 & Waterflooding + Polymer Flooding (1500 ppm) & & \\
\hline
\end{tabular}


Scenario 3 Waterflooding + Polymer Flooding (2000 ppm)

Heterogeneous Micromodel $90^{\circ}$ Orientation Angle (Pattern C)

Scenario 1 Waterflooding + Polymer Flooding (1000 ppm)

Scenario 2 Waterflooding + Polymer Flooding (1500 ppm)

$0.05 \mathrm{cc} / \mathrm{min}$

Low to High

Scenario 3 Waterflooding + Polymer Flooding (2000 ppm)

\section{Result and Discussion}

\subsection{Polymer Rheology Properties}

The measurement of FP3630S polymer viscosity at different concentrations is shown in Figure 6. As shown in Figure 6, at room temperature $\left(25^{\circ} \mathrm{C}\right)$, the polymer solution with concentrations $1000 \mathrm{ppm}, 1500 \mathrm{ppm}$ and $2000 \mathrm{ppm}$ will have a viscosity of $11.52 \mathrm{cp}, 24.34$ $\mathrm{cp}$ and $43 \mathrm{cp}$, respectively (at shear rate 7 1/s). Based on the graph of polymer viscosity vs concentration in Figure 6, it can be analysed that the increase of polymer concentration will result in higher viscosity. This result is used as the benchmark for polymer concentrations injected in a micromodel.

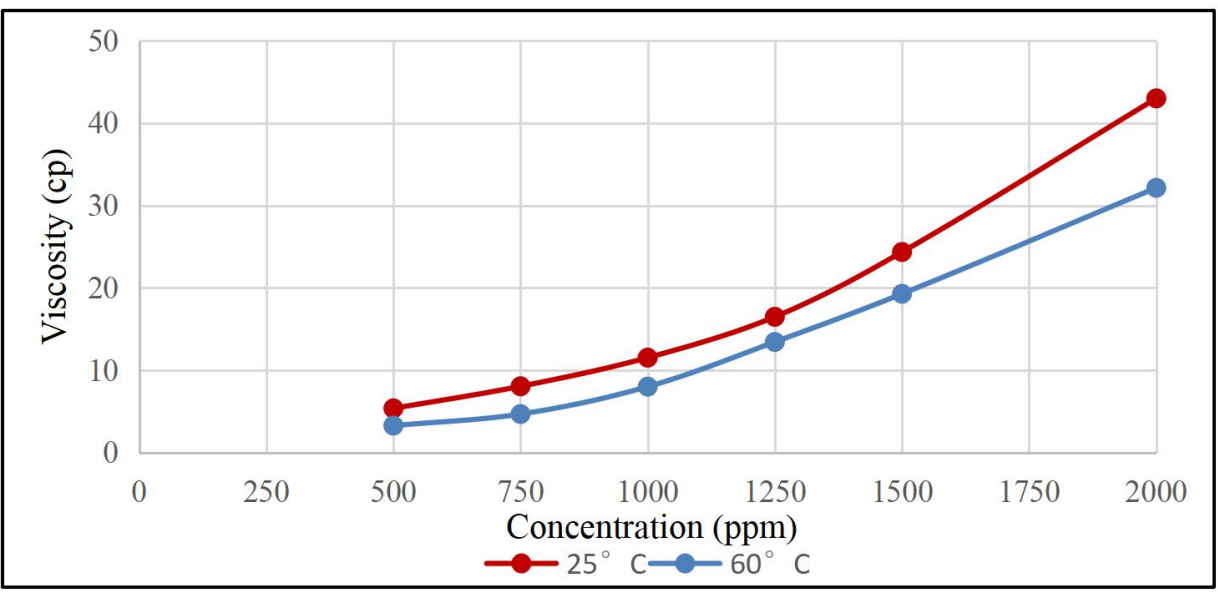

Figure 6. Viscosity vs Concentration of FP3630S Polymer at $25^{\circ} \mathrm{C}$ and $60^{\circ} \mathrm{C}$ (shear rate $71 / \mathrm{s}$ )

The measurement of FP3630S polymer viscosity at various shear rates for polymer solution with a concentration of $1000 \mathrm{ppm}, 1500 \mathrm{ppm}$ and $2000 \mathrm{ppm}$ are respectively shown in Figure 7, Figure 8 and Figure 9. According to all of those graphs, it can be seen that the polymer viscosity decreases as the shear rate increases, this behaviour is known as shear thinning or pseudoplastic fluid behaviour. According to this result, it proves that polymer is a nonnewtonian fluid. 


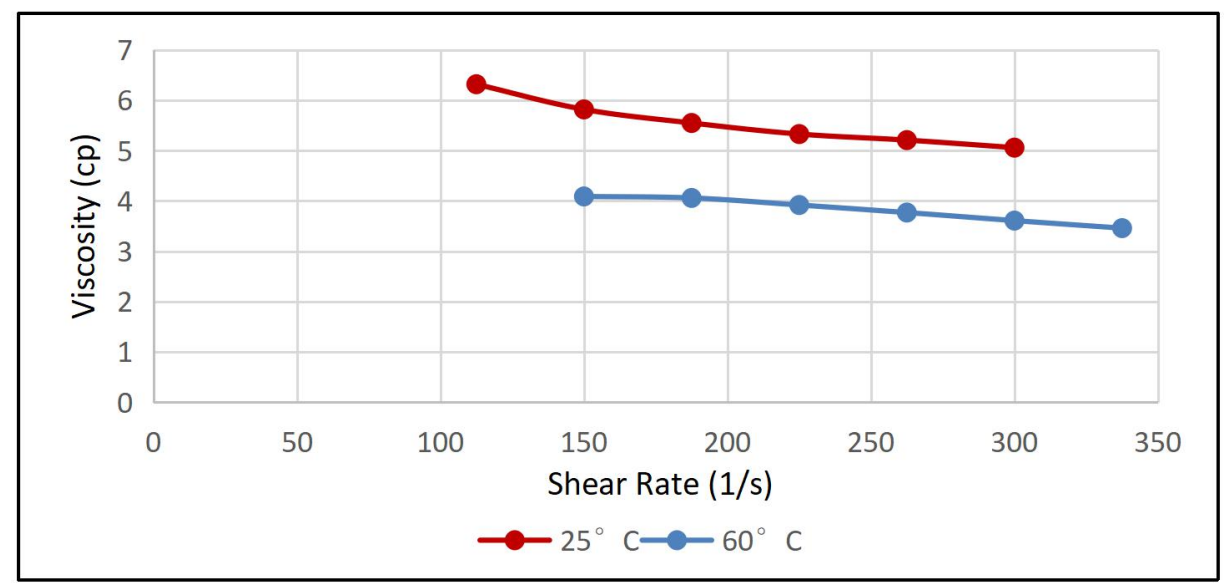

Figure 7. Viscosity vs Shear Rate of FP3630S Polymer (1000 ppm)

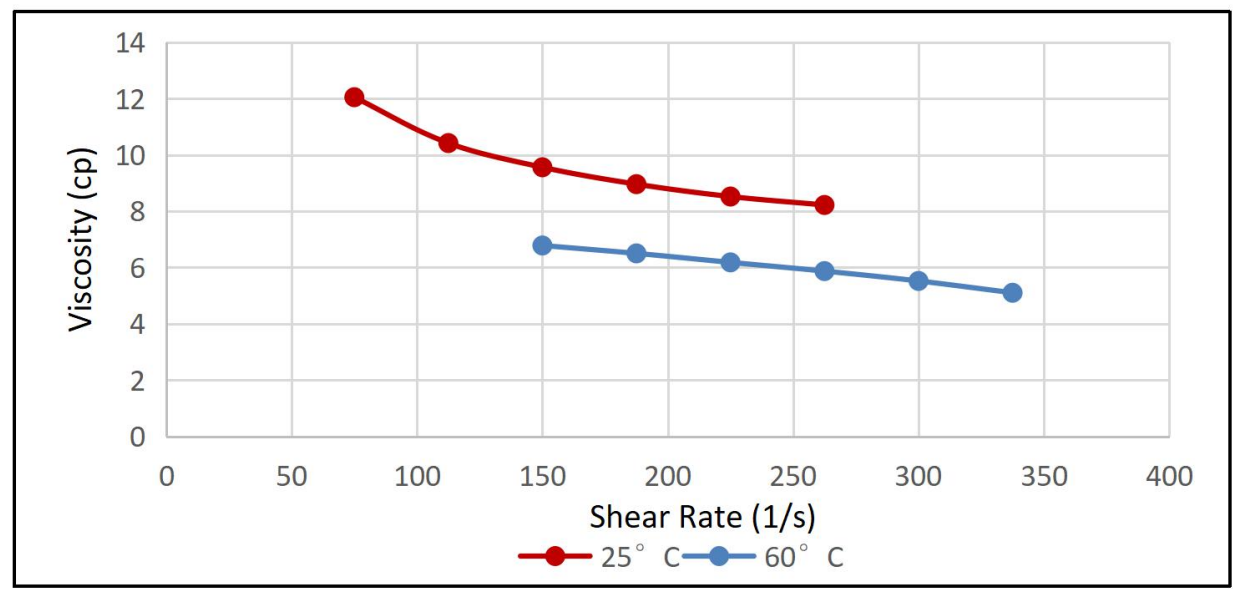

Figure 8. Viscosity vs Shear Rate of FP3630S Polymer (1500 ppm)

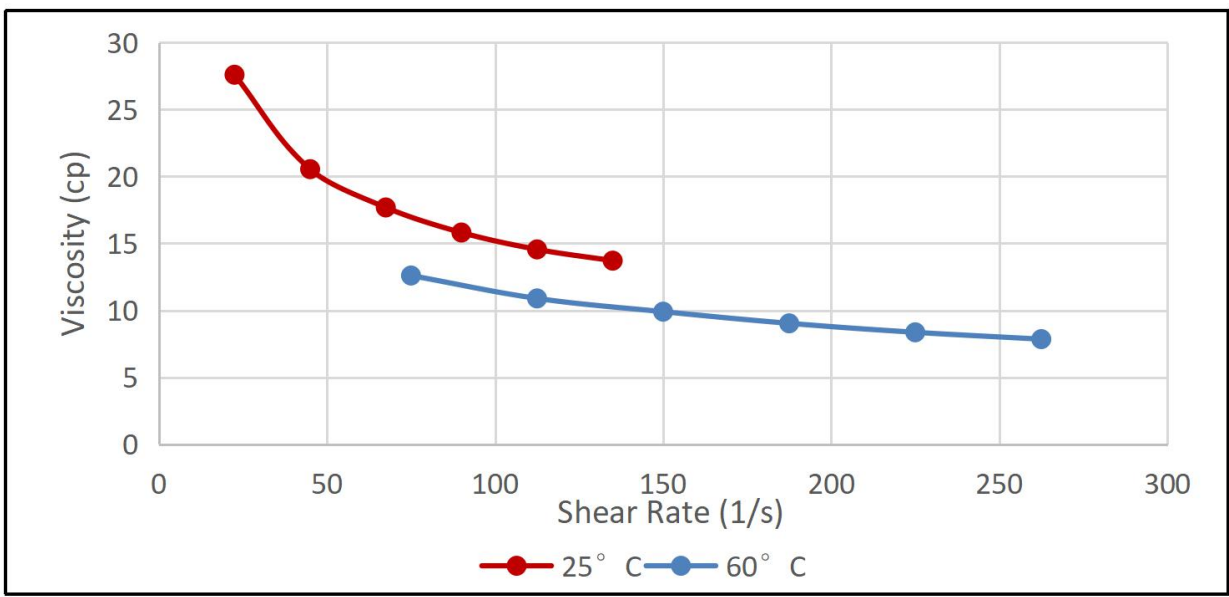

Figure 9. Viscosity vs Shear Rate of FP3630S Polymer (2000 ppm) 


\subsection{Polymer Aqueous Stability}

The result of aqueous stability test for seven days at $25^{\circ} \mathrm{C}$ and $60^{\circ} \mathrm{C}$ are shown in Figure 10 and Figure 11, respectively. Based on Figure 10 and Figure 11, it can be observed that there is no solid sediment is formed and the polymer solutions are still in a homogenous condition. It indicates that $\mathrm{FP} 3630 \mathrm{~S}$ polymer solution has good stability at $25^{\circ} \mathrm{C}$ and $60^{\circ} \mathrm{C}$. This method is used to obtain a good candidate of polymer type that will be used in the micromodel flooding test.

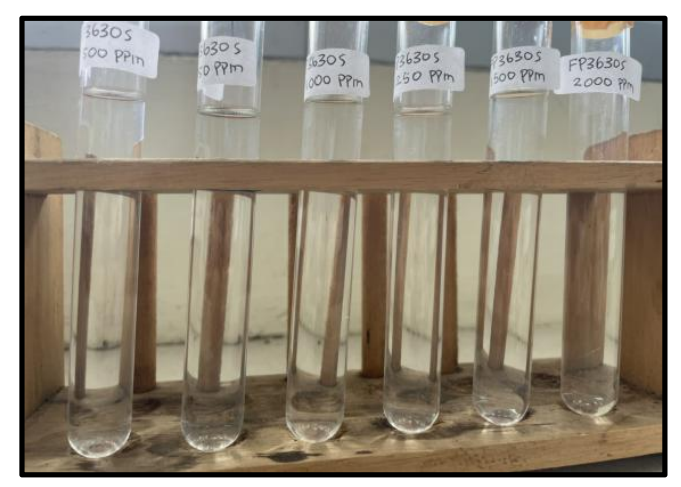

Figure 10. Polymer Aqueous Stability Test Result for Seventh-day at 25oC

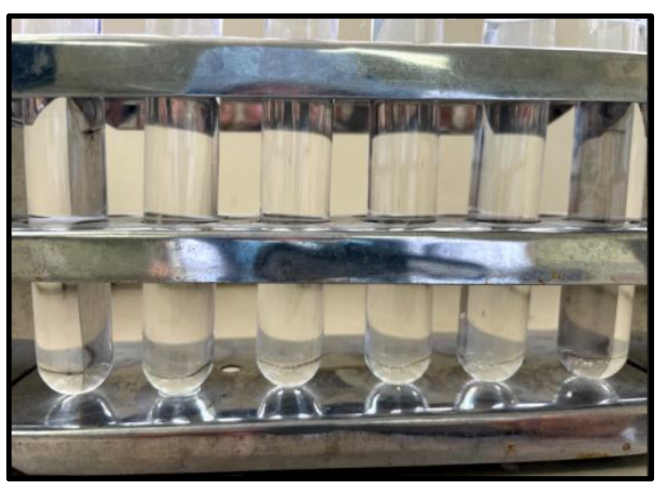

Figure 11. Polymer Aqueous Stability Test Result for Seventh-day at 60oC

\subsection{Micromodel Flooding Result}

The visualization of oil displacement mechanism for each scenario in pattern A, pattern B, pattern C (High to Low Permeability Zone) and pattern C (Low to High Permeability Zone) are shown in Figure 12, Figure 13, Figure 14 and Figure 15, respectively. Image processing (colour clustering) was performed to get each fluid saturation data based on the total pixels occupied by the fluid (oil, brine or polymer). Based on the saturation data, the oil recovery factor value for waterflooding and polymer injection process in each scenario can be calculated. 


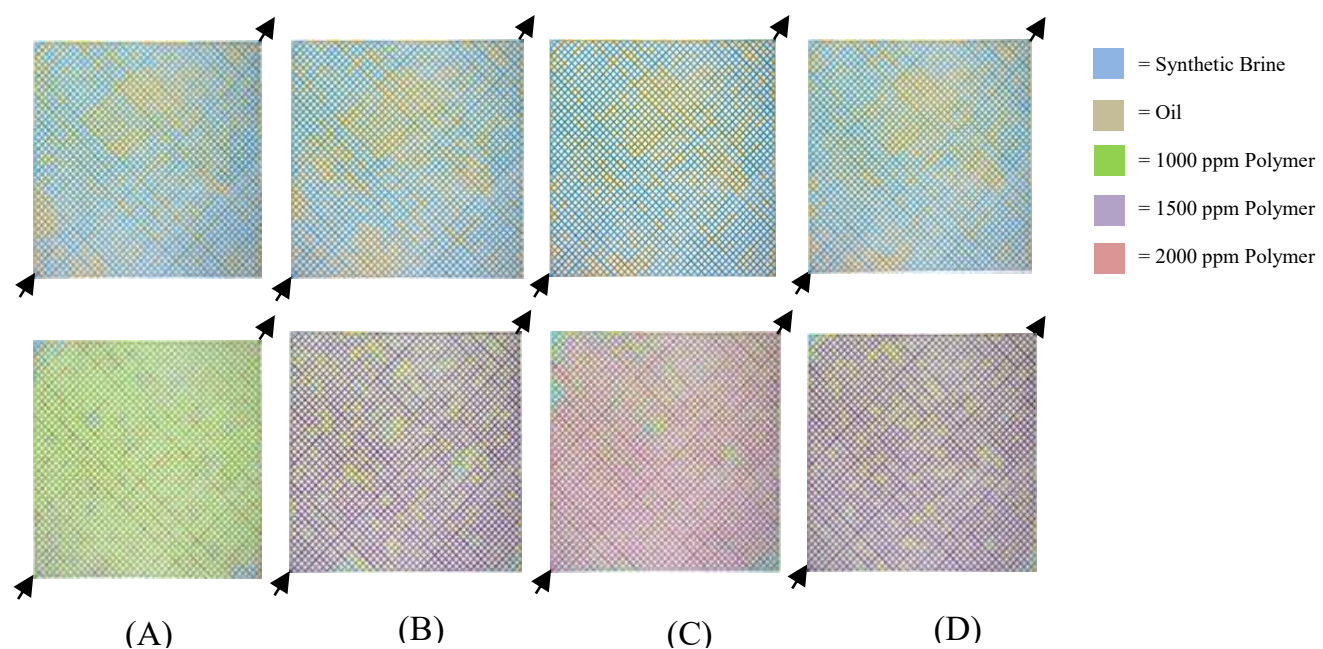

Figure 12. Visualization of Micromodel Flooding in Pattern $A$

Note: $\mathrm{A}=$ Scenario $1, \mathrm{~B}=$ Scenario 2, $\mathrm{C}=$ Scenario 3 (Injection Rate: $0.05 \mathrm{cc} / \mathrm{min}$ ) and $\mathrm{D}=$ Scenario 2 (Injection Rate: $0.08 \mathrm{cc} / \mathrm{min}$ )

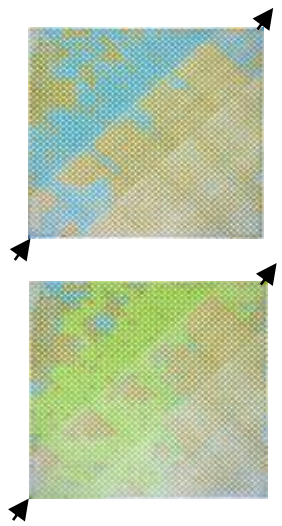

(A)

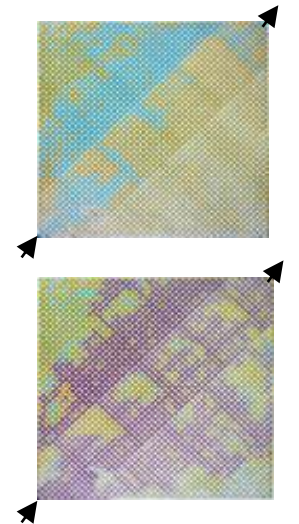

(B)

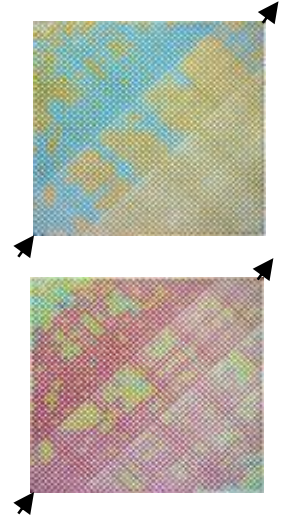

(C)

Figure 13. Visualization of Micromodel Flooding in Pattern B

Note: $\mathrm{A}=$ Scenario $1, \mathrm{~B}=$ Scenario 2 and $\mathrm{C}=$ Scenario 3 (Injection Rate: $0.05 \mathrm{cc} / \mathrm{min}$ )

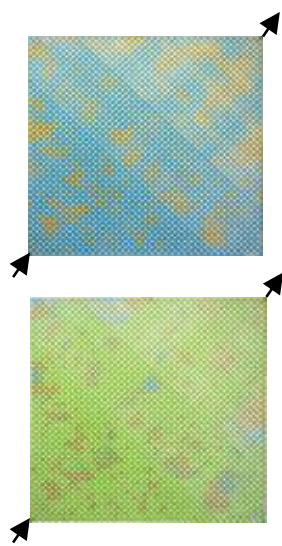

(A)

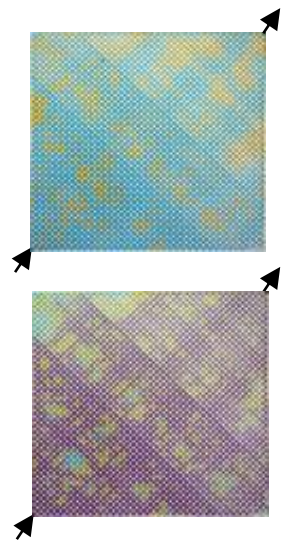

(B)

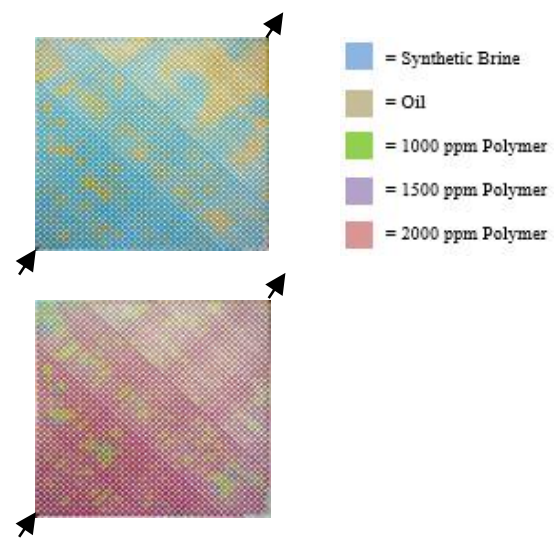

(C)

Figure 14. Visualization of Micromodel Flooding in Pattern $\mathrm{C}$

Note: $\mathrm{A}=$ Scenario $1, \mathrm{~B}=$ Scenario 2 and $\mathrm{C}=$ Scenario 3 (Injection Rate: $0.05 \mathrm{cc} / \mathrm{min}$ and Injection Process: High to Low Permeability Zone) 


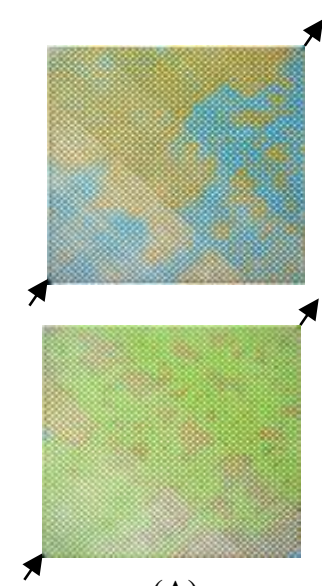

(A)

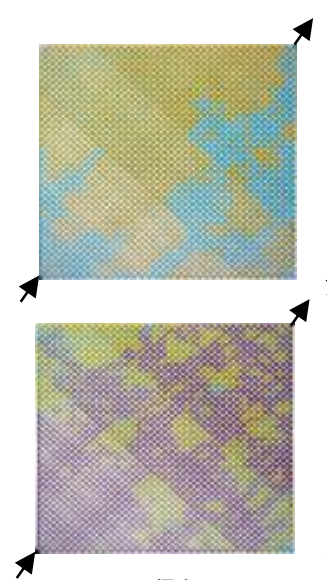

(B)

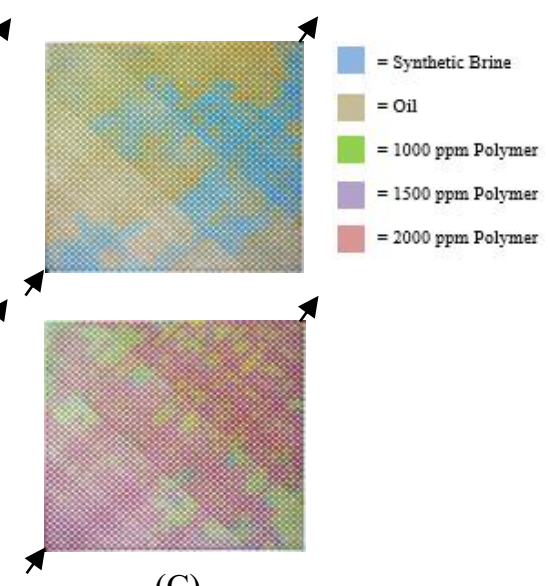

(C)

Figure 15. Visualization of Micromodel Flooding in Pattern C

Note: $\mathrm{A}=$ Scenario $1, \mathrm{~B}=$ Scenario 2 and $\mathrm{C}=$ Scenario 3 (Injection Rate: $0.05 \mathrm{cc} / \mathrm{min}$ and Injection Process: Low to High Permeability Zone)

\subsubsection{The Effect of Polymer Concentration}

All scenarios were conducted in each pattern (homogeneous and heterogeneous flow patterns) to examine the impact of polymer concentration on the performance of polymer injection in enhancing oil recovery. The graph of recovery factor value versus pore volume injected resulted from each scenario in pattern A, pattern B, pattern C (High to Low Permeability Zone) and Pattern C (Low to High Permeability Zone) are respectively shown in Figure 16, Figure 18, Figure 20 and Figure 22. The incremental oil recovery factor generated from the injection of polymer solution with different concentrations in pattern $\mathrm{A}$, pattern $\mathrm{B}$, pattern $\mathrm{C}$ (High to Low Permeability Zone) and Pattern C (Low to High Permeability Zone) are shown in Figure 17, Figure 19, Figure 21 and Figure 23, respectively. Table 3, Table 4, Table 5 and Table 6 also display the recovery factor value after waterflooding and polymer injection. Based on the experimental results, it can be analysed that the increase in polymer concentration will make the displacing fluid viscosity become greater, resulting in a more favourable mobility ratio. Therefore, the sweep efficiency will be better due to the oil displacement is more piston-like. The better sweep efficiency, the higher incremental oil recovery achieved. According to this analysis, polymer injection with a concentration of 2000 ppm (scenario 3) that is conducted in homogeneous and heterogeneous micromodel generates the highest incremental oil recovery among the other scenario. It proves that mobility ratio has an essential role in the implementation of polymer injection for improving oil recovery. Therefore, mobility ratio design must be conducted before implementing polymer injection to get optimum result. 


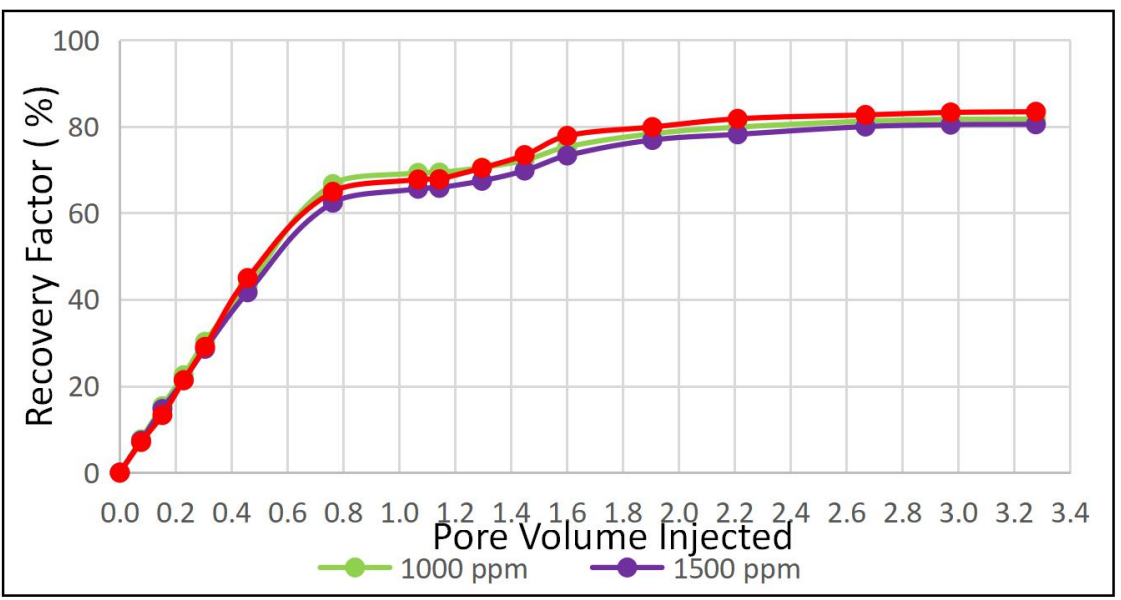

Figure 16. Oil Recovery Factor vs Pore Volume Injected of Each Scenario in Pattern A (Injection Rate: 0.05 cc/min)

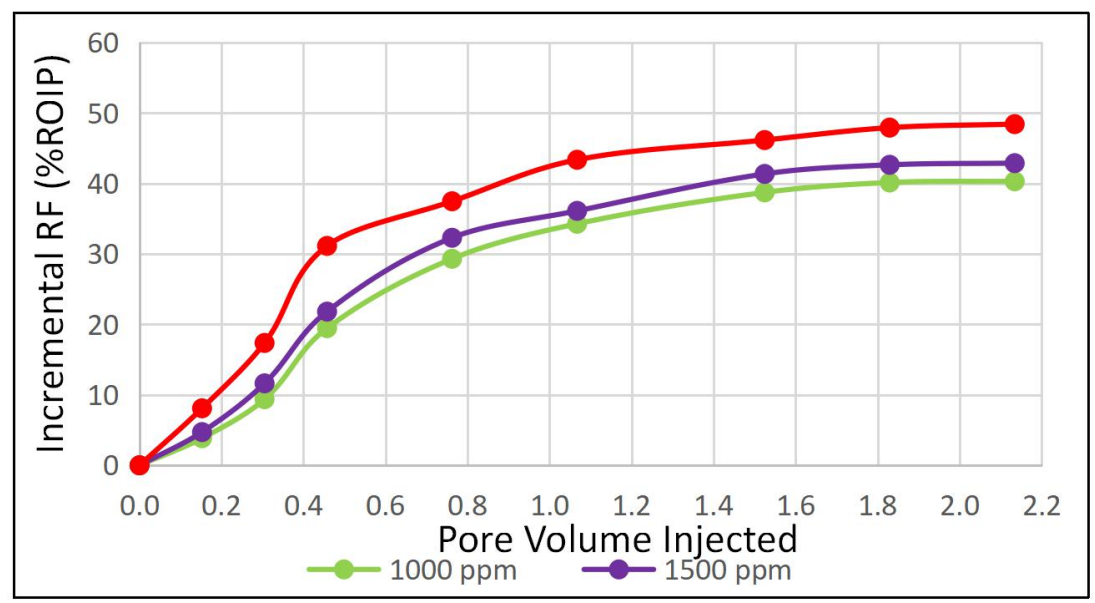

Figure 17. Incremental Oil Recovery Factor vs Pore Volume Injected of Each Scenario in Pattern A (Injection Rate: 0.05 cc/min)

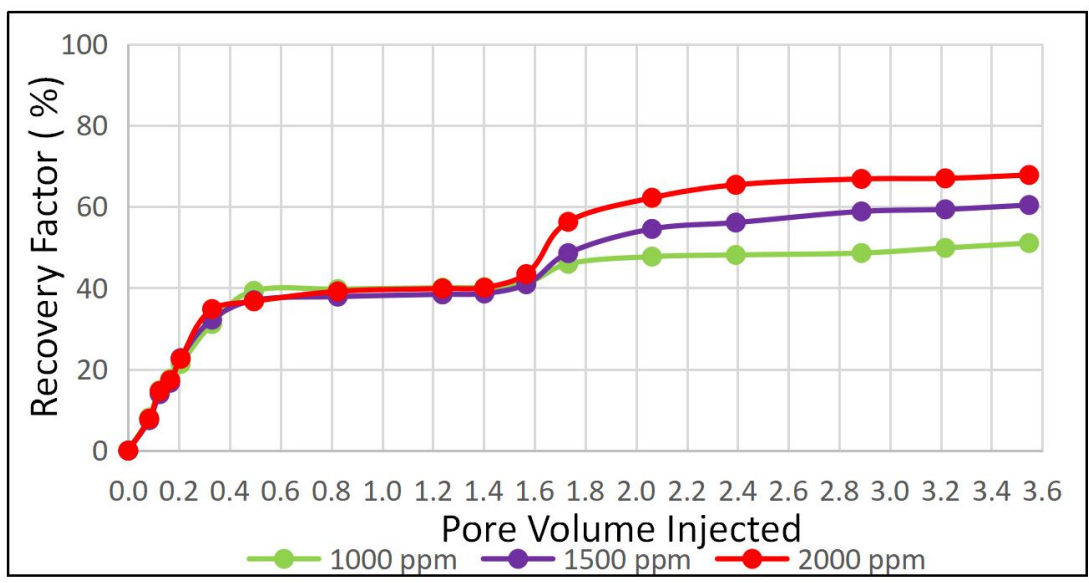

Figure 18. Oil Recovery Factor vs Pore Volume Injected of Each Scenario in Pattern B (Injection Rate: 0.05 cc/min) 


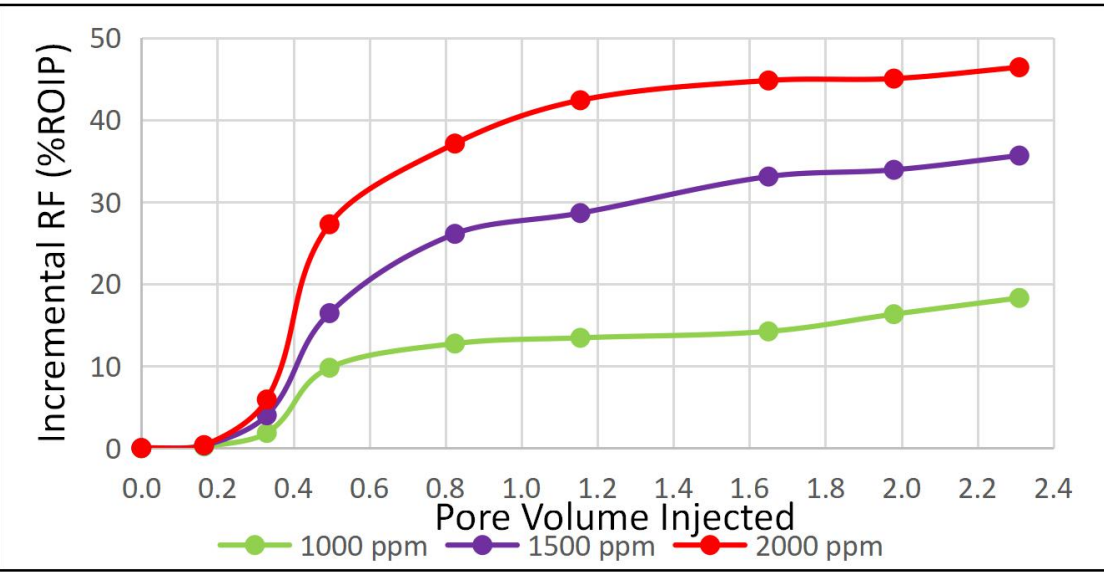

Figure 19. Incremental Oil Recovery Factor vs Pore Volume Injected of Each Scenario in Pattern B (Injection Rate: $0.05 \mathrm{cc} / \mathrm{min}$ )

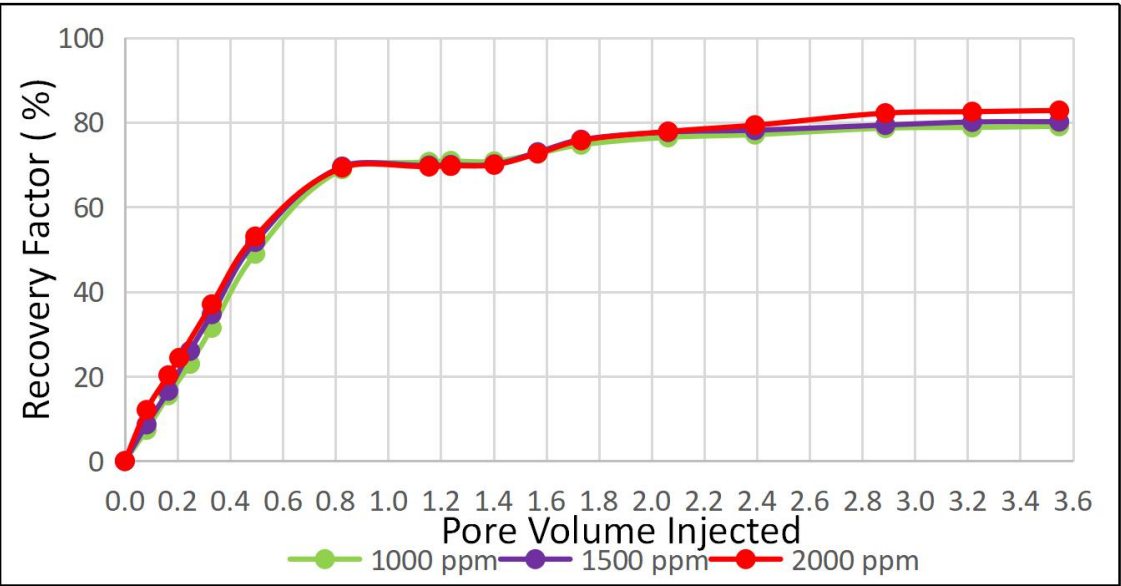

Figure 20. Oil Recovery Factor vs Pore Volume Injected of Each Scenario in Pattern C (Injection Rate: 0.05 cc/min and Injection Process: High to Low Permeability Zone)

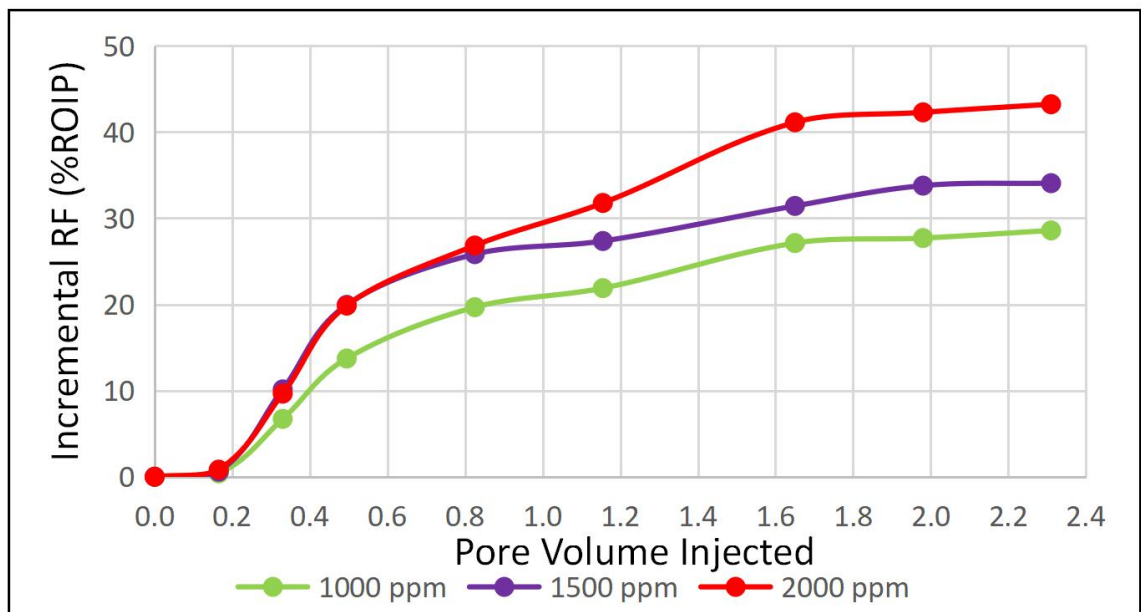

Figure 21. Incremental Oil Recovery Factor vs Pore Volume Injected of Each Scenario in Pattern C (Injection Rate: 0.05 cc/min and Injection Process: High to Low Permeability Zone) 


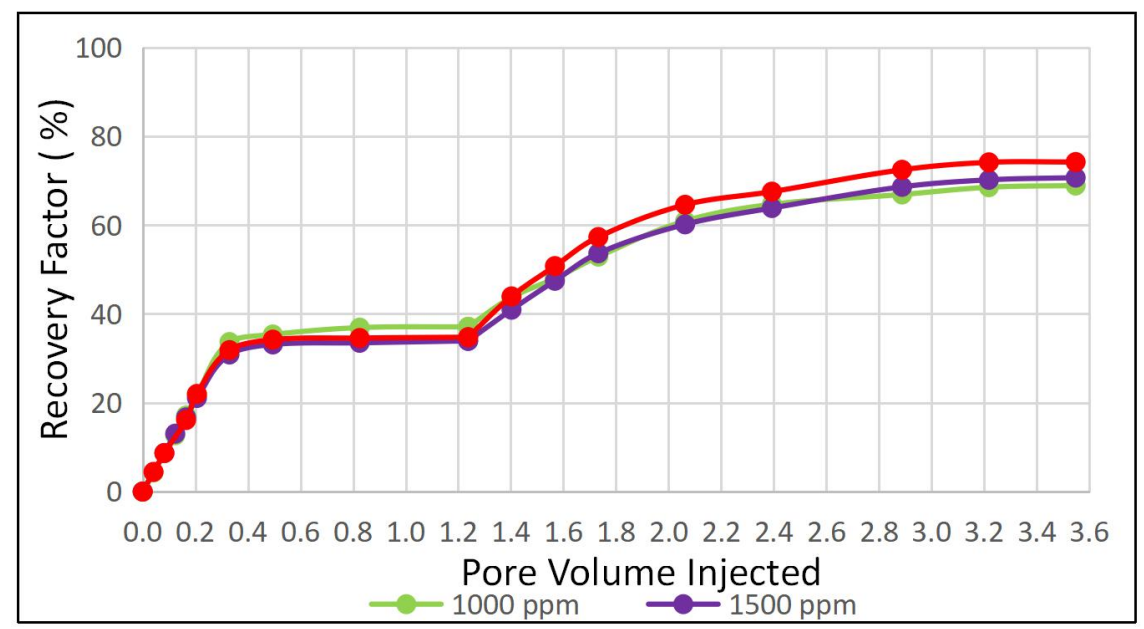

Figure 22. Oil Recovery Factor vs Pore Volume Injected of Each Scenario in Pattern C (Injection Rate: 0.05 cc/min and Injection Process: Low to High Permeability Zone)

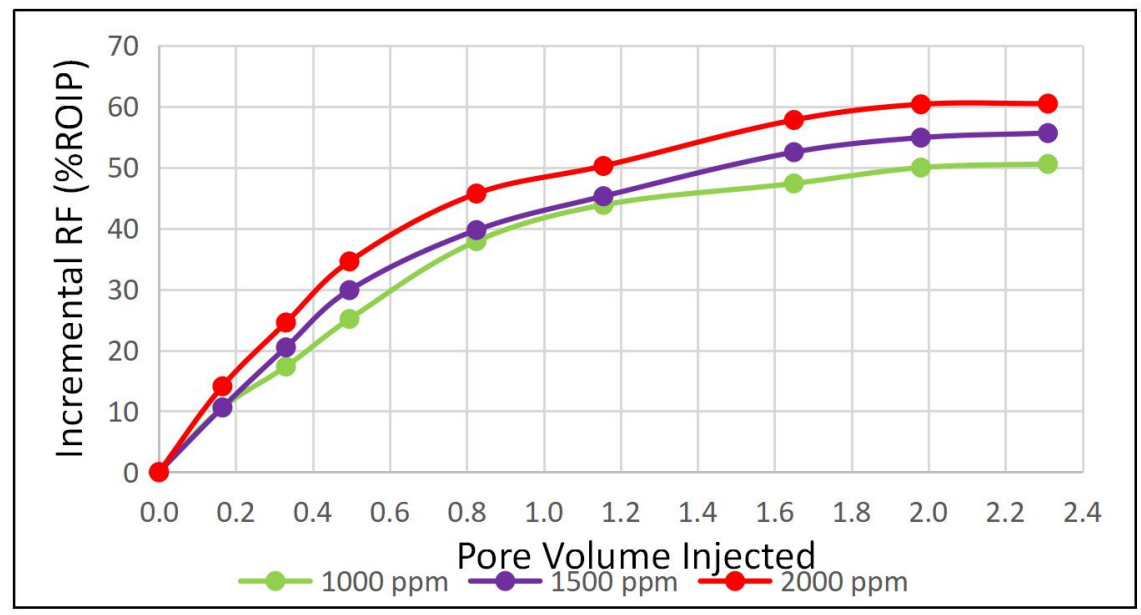

Figure 23. Incremental Oil Recovery Factor vs Pore Volume Injected of Each Scenario in Pattern C (Injection Rate: 0.05 cc/min and Injection Process: Low to High Permeability Zone)

Table 3. Oil Recovery Factor of Each Scenario in Pattern A

\begin{tabular}{ccccc}
\hline $\begin{array}{c}\text { Concentration } \\
(\mathbf{p p m})\end{array}$ & $\begin{array}{c}\text { Waterflooding RF } \\
\mathbf{( \% )}\end{array}$ & $\begin{array}{c}\text { Polymer Injection RF } \\
\mathbf{( \% )}\end{array}$ & $\begin{array}{c}\text { Incremental } \\
(\mathbf{\%} \text { OOIP) }\end{array}$ & $\begin{array}{c}\text { Incremental } \\
(\mathbf{\%} \text { ROIP) }\end{array}$ \\
\hline 1000 & 69.29 & 81.67 & 12.38 & 40.31 \\
1500 & 65.80 & 80.47 & 14.66 & 42.88 \\
2000 & 67.76 & 83.37 & 15.61 & 48.42 \\
\hline
\end{tabular}


Table 4. Oil Recovery Factor of Each Scenario in Pattern B

\begin{tabular}{ccccc}
\hline $\begin{array}{c}\text { Concentration } \\
(\mathbf{p p m})\end{array}$ & $\begin{array}{c}\text { Waterflooding RF } \\
\mathbf{( \% )}\end{array}$ & $\begin{array}{c}\text { Polymer Injection } \\
\mathbf{R F}(\mathbf{\%})\end{array}$ & $\begin{array}{c}\text { Incremental } \\
(\mathbf{\% O O I P )}\end{array}$ & $\begin{array}{c}\text { Incremental } \\
(\mathbf{\%} \text { ROIP) }\end{array}$ \\
\hline 1000 & 40.06 & 51.03 & 10.97 & 18.31 \\
1500 & 38.44 & 60.39 & 21.95 & 35.66 \\
2000 & 39.85 & 67.78 & 27.93 & 46.43 \\
\hline
\end{tabular}

Table 5. Oil Recovery Factor of Each Scenario in Pattern C

(Injected from High to Low Permeability Zone)

\begin{tabular}{ccccc}
\hline $\begin{array}{c}\text { Concentration } \\
(\mathbf{p p m})\end{array}$ & $\begin{array}{c}\text { Waterflooding RF } \\
\mathbf{( \% )}\end{array}$ & $\begin{array}{c}\text { Polymer } \\
\text { Injection RF } \\
(\mathbf{\%})\end{array}$ & $\begin{array}{c}\text { Incremental } \\
(\mathbf{\%} \text { OOIP) }\end{array}$ & $\begin{array}{c}\text { Incremental } \\
\mathbf{( \% R O I P )}\end{array}$ \\
\hline 1000 & 70.86 & 79.05 & 8.38 & 28.58 \\
1500 & 69.91 & 80.16 & 10.25 & 34.06 \\
2000 & 69.72 & 82.80 & 13.09 & 43.21 \\
\hline
\end{tabular}

Table 6. Oil Recovery Factor of Each Scenario in Pattern C

(Injected from Low to High Permeability Zone)

\begin{tabular}{ccccc}
\hline $\begin{array}{c}\text { Concentration } \\
(\mathbf{p p m})\end{array}$ & $\begin{array}{c}\text { Waterflooding RF } \\
\mathbf{( \% )}\end{array}$ & $\begin{array}{c}\text { Polymer } \\
\text { Injection RF } \\
\mathbf{( \% )}\end{array}$ & $\begin{array}{c}\text { Incremental } \\
\mathbf{( \% O O I P )}\end{array}$ & $\begin{array}{c}\text { Incremental } \\
\text { (\% ROIP) }\end{array}$ \\
\hline 1000 & 37.10 & 68.90 & 31.81 & 50.56 \\
1500 & 33.93 & 72.02 & 38.09 & 57.65 \\
2000 & 34.21 & 73.98 & 39.77 & 60.45 \\
\hline
\end{tabular}

\subsubsection{The Effect of Reservoir Heterogeneity}

All patterns (homogeneous and heterogeneous flow patterns) were used as the porous medium to evaluate the effect of reservoir heterogeneity (permeability variation and different orientation angle) on the oil recovery factor. Recovery factor versus pore volume injected generated by scenario 1, scenario 2 and scenario 3 in each pattern are respectively shown in Figure 24, Figure 26 and Figure 28. The incremental oil recovery value resulted from the injection of polymer solution with various concentrations in each pattern are shown in Figure 25, Figure 27 and Figure 29, respectively. Table 7, Table 8 and Table 9 also present the recovery factor for waterflooding and polymer injection process. Based on the result of waterflooding process, it can be seen that the highest average recovery factor is obtained in pattern $\mathrm{C}$ if the water is injected from high permeability zone. Otherwise, the lowest average recovery factor will be obtained in pattern $\mathrm{C}$ if the injection process starts from low 
permeability zone. This can happen because the injected fluid will look for a path with the lowest flow resistance to the production port, in which a zone with the highest permeability will have the lowest flow resistance. Therefore, the distribution of injected water will be more even if the water flows through a zone with high permeability first. It will result in a large amount of bypassed oil if the water meets low permeability zone first where severe viscous fingering effect will happen due to permeability variation resulting in early water breakthrough that the water flow cannot find more new flow paths to displace oil, thus lower recovery factor will be achieved. Pattern B also gives low oil recovery after conducting waterflooding process, where the parallel layers in the micromodel makes the water only dominant flows through a zone with the highest permeability which leads to the early water breakthrough. However, the result is still higher than the oil recovery obtained in pattern $\mathrm{C}$ if the water is injected from low permeable zone.

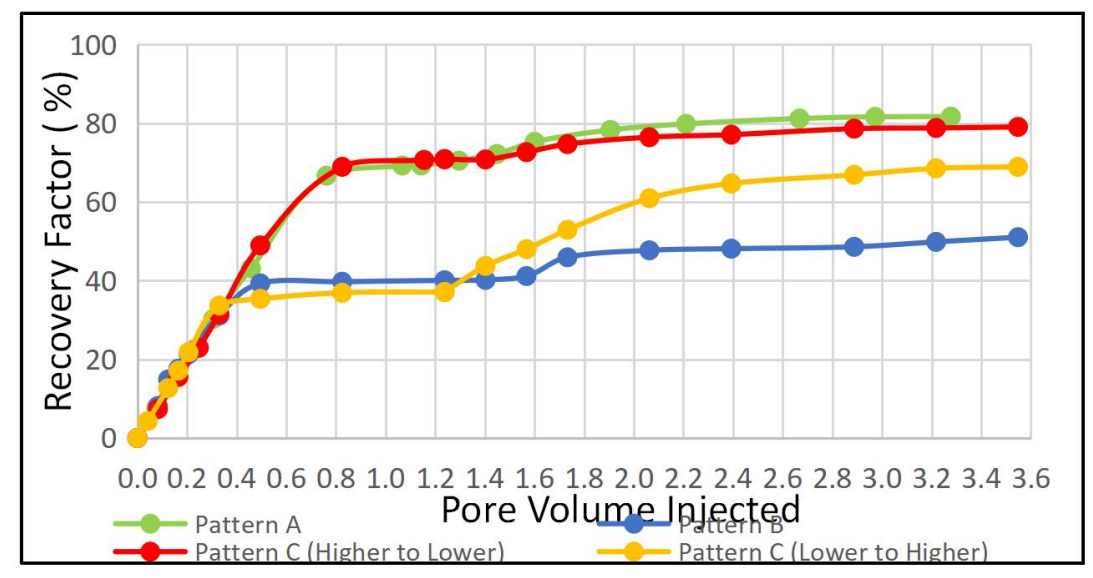

Figure 24. Oil Recovery Factor vs Pore Volume Injected of Scenario 1 in Each Pattern (Injection Rate: 0.05 cc/min)

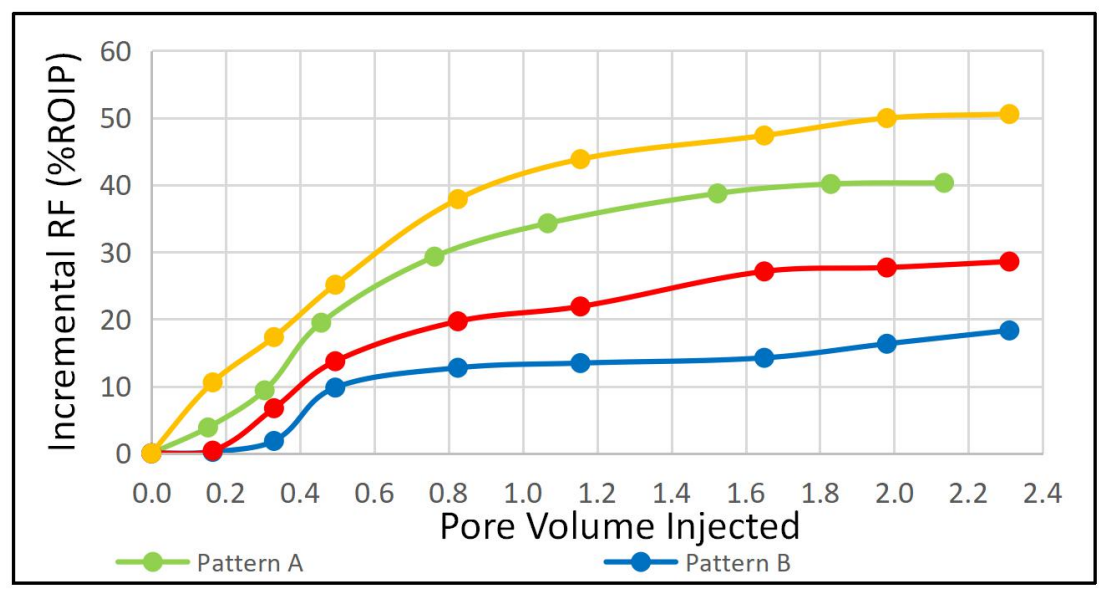

Figure 25. Incremental Oil Recovery Factor vs Pore Volume Injected of Scenario 1 in Each Pattern (Injection Rate: $0.05 \mathrm{cc} / \mathrm{min}$ ) 


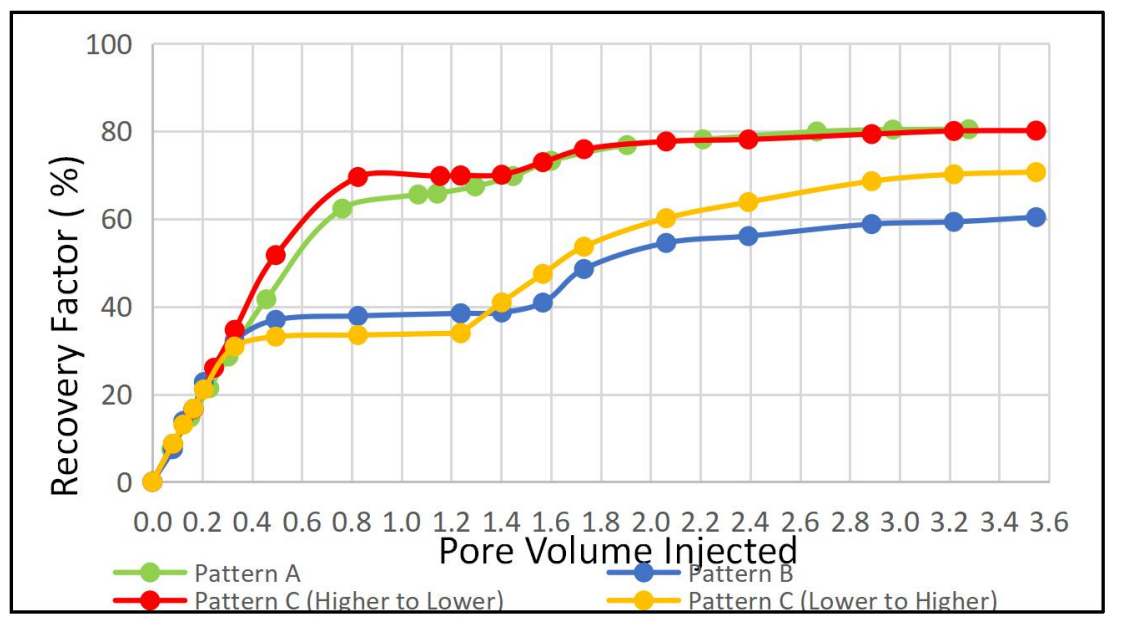

Figure 26. Oil Recovery Factor vs Pore Volume Injected of Scenario 2 in Each Pattern (Injection Rate: 0.05 cc/min)

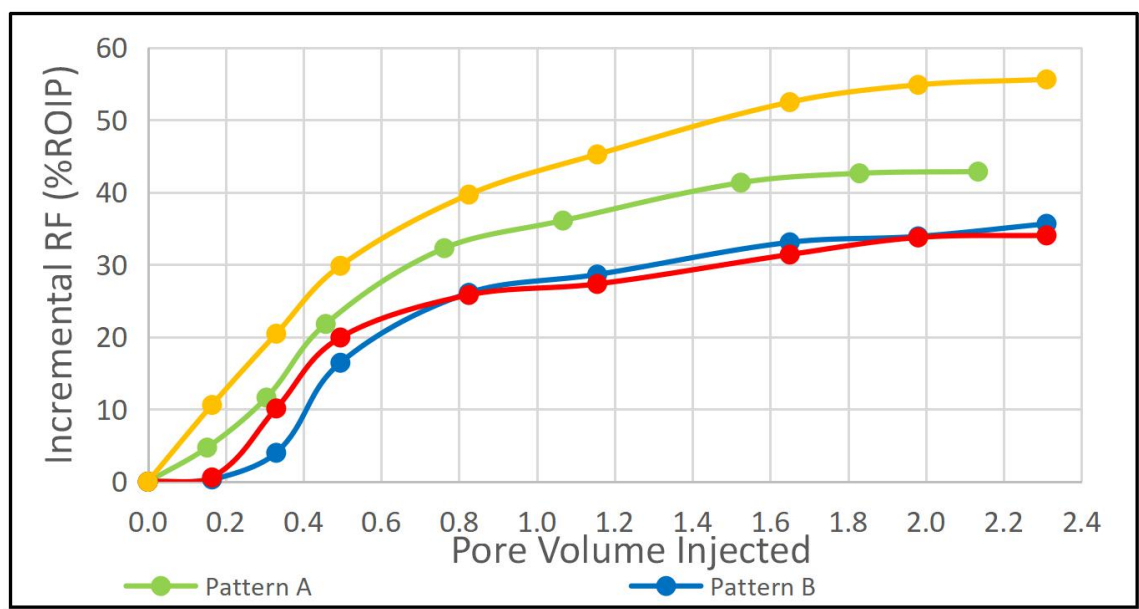

Figure 27. Incremental Oil Recovery Factor vs Pore Volume Injected of Scenario 2 in Each Pattern (Injection Rate: 0.05 cc/min)

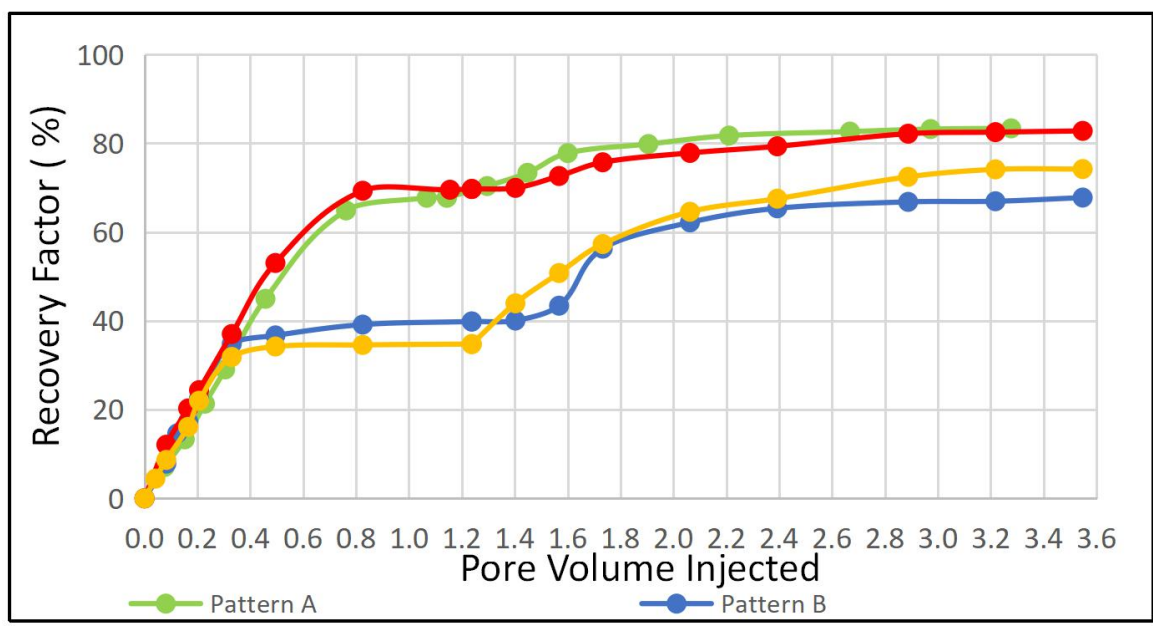

Figure 28. Oil Recovery Factor vs Pore Volume Injected of Scenario 3 in Each Pattern (Injection Rate: 0.05 cc/min) 


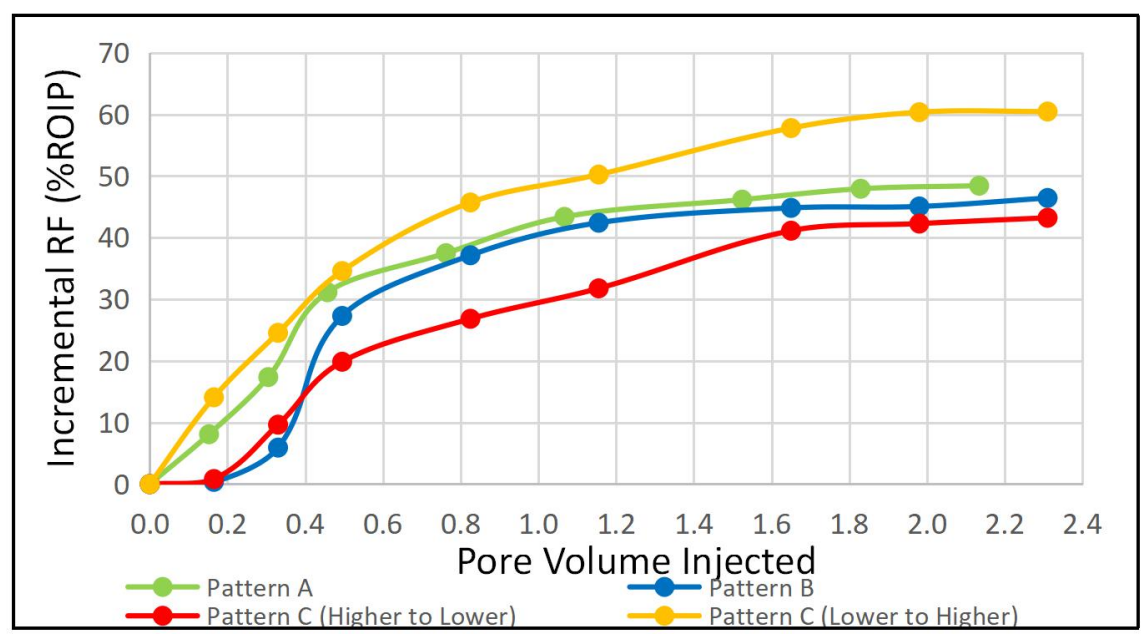

Figure 29. Incremental Oil Recovery Factor vs Pore Volume Injected of Scenario 3 in Each Pattern (Injection Rate: 0.05 cc/min)

Table 7. Oil Recovery Factor of Scenario 1 in Each Pattern

\begin{tabular}{ccccc}
\hline Pattern & $\begin{array}{c}\text { Waterflooding } \\
\text { RF (\%) }\end{array}$ & $\begin{array}{c}\text { Polymer Injection RF } \\
(\mathbf{\%})\end{array}$ & $\begin{array}{c}\text { Incremental } \\
(\mathbf{\%} \text { OOIP) }\end{array}$ & $\begin{array}{c}\text { Incremental } \\
\text { (\% ROIP) }\end{array}$ \\
\hline A & 69.29 & 81.67 & 12.38 & 40.31 \\
B & 40.06 & 51.03 & 10.97 & 18.31 \\
C (High to Low) & 70.86 & 79.05 & 8.38 & 28.58 \\
C (Low to High) & 37.10 & 68.9 & 31.81 & 50.56 \\
\hline
\end{tabular}

Table 8. Oil Recovery Factor of Scenario 2 in Each Pattern

\begin{tabular}{ccccc}
\hline Pattern & $\begin{array}{c}\text { Waterflooding } \\
\text { RF (\%) }\end{array}$ & $\begin{array}{c}\text { Polymer Injection RF } \\
(\mathbf{\%})\end{array}$ & $\begin{array}{c}\text { Incremental } \\
(\mathbf{\% O O I P )}\end{array}$ & $\begin{array}{c}\text { Incremental } \\
\text { (\%ROIP) }\end{array}$ \\
\hline $\mathrm{A}$ & 65.80 & 80.47 & 14.66 & 42.88 \\
$\mathrm{~B}$ & 38.44 & 60.39 & 21.95 & 35.66 \\
C (High to Low) & 69.91 & 80.16 & 10.25 & 34.06 \\
C (Low to High) & 33.93 & 72.02 & 38.09 & 57.65 \\
\hline
\end{tabular}

Table 9. Oil Recovery Factor of Scenario 3 in Each Pattern

\begin{tabular}{ccccc}
\hline Pattern & $\begin{array}{c}\text { Waterflooding } \\
\text { RF (\%) }\end{array}$ & $\begin{array}{c}\text { Polymer Injection RF } \\
(\mathbf{\%})\end{array}$ & $\begin{array}{c}\text { Incremental } \\
(\mathbf{\%} \text { OOIP) }\end{array}$ & $\begin{array}{c}\text { Incremental } \\
\text { (\% ROIP) }\end{array}$ \\
\hline A & 67.76 & 83.37 & 15.61 & 48.42 \\
B & 39.85 & 67.78 & 27.93 & 46.43 \\
C (High to Low) & 69.72 & 82.80 & 13.09 & 43.21 \\
C (Low to High) & 34.21 & 73.98 & 39.77 & 60.45 \\
\hline
\end{tabular}


The result of waterflooding in each micromodel will influence on the performance of polymer injection in improving oil recovery. Based on the incremental oil recovery value resulted by polymer injection in each micromodel, it can be analysed that all scenarios in pattern $\mathrm{C}$ will have the highest incremental oil recovery if the injection process starts from low permeability zone. It can happen because there is still high fraction of residual oil in the micromodel due to low sweep efficiency of waterflooding process and the implementation of polymer injection can minimize the effect of permeability variation in the micromodel. The injection of polymer in pattern $\mathrm{C}$ provides the lowest incremental oil recovery (except scenario 1) when the injection port is in high permeability zone as a result of the waterflooding process already generated high oil recovery which is similar to the result in pattern A (homogenous flow pattern). It proves that pattern $\mathrm{C}$ (micromodel with $90^{\circ}$ orientation angle or perpendicular to the mean flow direction) will have the lowest flow resistance if the injection process starts from a zone that has high permeability. Therefore, the injected polymer cannot give significant improvement due to the remaining oil is already low and polymer displaces more water than oil itself.

For scenario 1 that was conducted in pattern $\mathrm{B}$ will result in the lowest incremental oil recovery among the other pattern even there is still high amount of remaining oil in the micromodel. It can occur due to the injection of $1000 \mathrm{ppm}$ polymer still not enough to minimize the effect of disproportionate permeability in the micromodel, where permeability variation effect caused by the layers are parallel to the mean flow direction resulting in poor fluid flow distribution, this condition makes polymer solution cannot find more new flow paths in the lower permeable zone to contact with more oil and the injected polymer prefer to flow through the path that has been passed by water. Thus, it needs higher concentration to get more favourable mobility ratio so that the polymer solution can displace more oil in the lower permeable zone. This analysis is proven by the result of polymer injection with higher concentration (1500 ppm and $2000 \mathrm{ppm})$ in this micromodel type. The result reveals that in pattern $\mathrm{B}$ (micromodel with $0^{\circ}$ orientation angle or parallel to the mean flow direction), scenario 2 and scenario 3 did not give the lowest incremental oil recovery.

Based on the micromodel flooding test, it can be observed that polymer injection can enhance oil recovery factor significantly in all patterns. It proves that polymer can reduce the effect of permeability variation by diverting the injected water from zones that have been swept to a zone that still contains more oil. However, oil recovery obtained is strongly affected by the heterogeneity around the injection port that can give significant impact on the sweep 
efficiency of waterflooding and polymer injection process that causes the incremental oil recovery generated in pattern $\mathrm{C}$ can be higher or lower compared to the result in pattern $\mathrm{A}$. Therefore, reservoir heterogeneity should be identified first to understand the reservoir condition that can give significant impact on the performance of polymer injection.

\subsubsection{The Effect of Injection Flow Rate}

In the implementation of scenario 2 in pattern A (homogenous micromodel), different injection flow rates were used to understand the influence of flow rate on the oil recovery factor. Recovery factor value versus pore volume injected resulted from scenario 2 in pattern A with the injection rates of 0.05 and $0.08 \mathrm{cc} / \mathrm{min}$ is shown in Figure 30. The incremental oil recovery generated by the injection of $1500 \mathrm{ppm}$ polymer solution in pattern A with different injection rates is presented by Figure 31. Table 10 also displays the recovery factor obtained after waterflooding and polymer injection process. According to the results, it can be analysed that the injection of polymer with a concentration of $1500 \mathrm{ppm}$ (scenario 2) at lower injection rate $(0.05 \mathrm{cc} / \mathrm{min})$ provides higher incremental oil recovery. It can happen because at lower injection rate, polymer solution will have more time to distribute areally through the flow path in the micromodel which result in more stable flood front and more piston-like displacement. Thus, more oil will be displaced by the injected polymer resulting in higher incremental oil recovery. This analysis is clearly proven by Figure 31 and Table 10, where the incremental oil recovery value is higher when lower injection rate $(0.05 \mathrm{cc} / \mathrm{min})$ is implemented. From this result, it proves that injection rate also gives an impact on the performance of polymer injection in enhancing oil recovery. Therefore, it should be considered before conducting polymer injection to achieve optimum result.

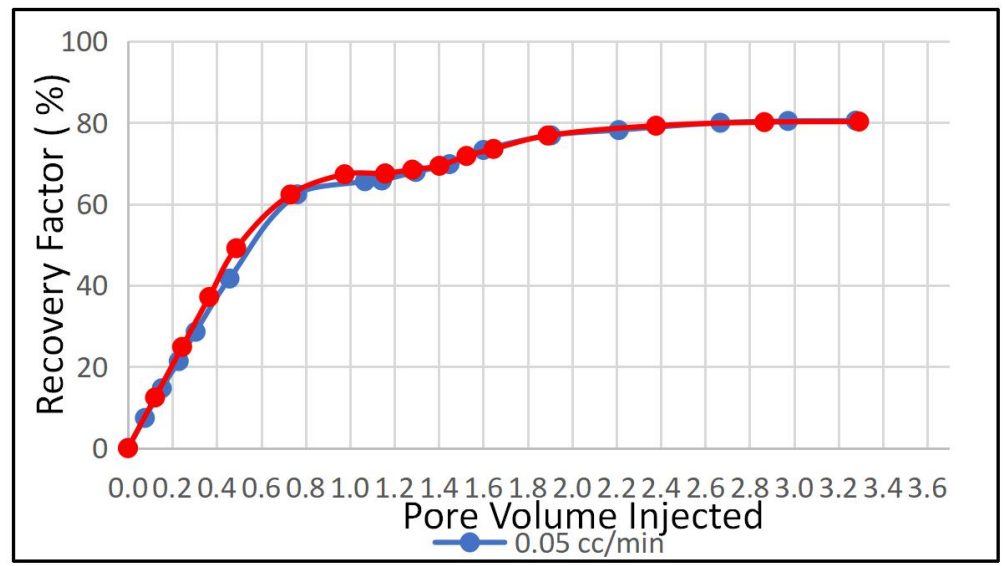

Figure 30. Oil Recovery Factor vs Pore Volume Injected of Scenario 2 in Pattern A (Injection Rate: $0.05 \mathrm{cc} / \mathrm{min}$ and $0.08 \mathrm{cc} / \mathrm{min})$ 


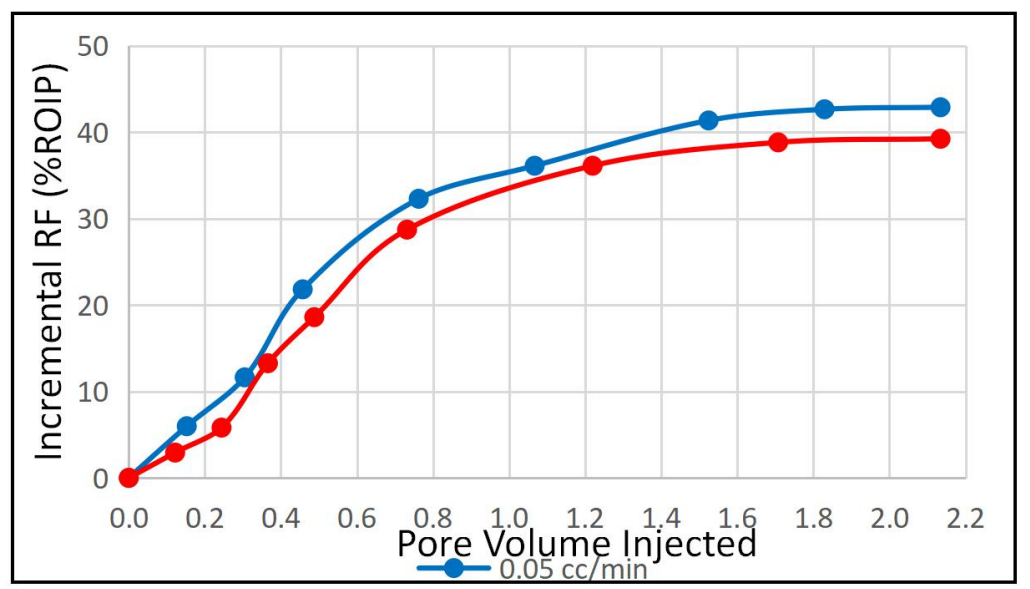

Figure 31. Incremental Oil Recovery Factor vs Pore Volume Injected of Scenario 2 in Pattern A (Injection Rate: $0.05 \mathrm{cc} / \mathrm{min}$ and $0.08 \mathrm{cc} / \mathrm{min}$ )

Table 10. Oil Recovery Factor of Scenario 2 in Pattern A with Different Injection Rates

\begin{tabular}{c|c|c|c|c}
\hline $\begin{array}{c}\text { Injection Rate } \\
\text { (cc/min) }\end{array}$ & $\begin{array}{c}\text { Waterflooding } \\
\text { RF (\%) }\end{array}$ & $\begin{array}{c}\text { Polymer Injection } \\
\text { RF (\%) }\end{array}$ & $\begin{array}{c}\text { Incremental } \\
\text { (\%OOIP) }\end{array}$ & $\begin{array}{c}\text { Incremental } \\
\text { (\%ROIP) }\end{array}$ \\
\hline 0.05 & 65.80 & 80.47 & 14.66 & 42.88 \\
0.08 & 67.47 & 80.23 & 12.76 & 39.24 \\
\hline
\end{tabular}

\section{Conclusion}

Based on the experimental study of polymer injection in micromodel that has been conducted, it can be referred as follows:

1. In homogeneous and heterogeneous micromodel, polymer injection with higher concentration will result in higher incremental oil recovery due to better sweep efficiency.

2. Micromodel with $90^{\circ}$ orientation angle will give the highest recovery factor for waterflooding among the other micromodel if the water is injected from high permeability zone. However, the lowest recovery factor will be obtained if the water was injected from the opposite direction.

3. For polymer injection scenario, the highest incremental oil recovery is obtained in micromodel with $90^{\circ}$ orientation angle when the injection is from low permeability zone due to the residual oil saturation is still high and the using of polymer can minimize the effect of permeability variation in the micromodel.

4. The lowest incremental oil recovery is obtained in micromodel with $90^{\circ}$ orientation angle when the injection port is in high permeability zone (except scenario 1), it can happen 
because the waterflooding process already gave high oil recovery, thus the remaining oil in the micromodel is already low that makes polymer injection cannot give significant incremental oil recovery.

5. For scenario 1 (waterflooding $+1000 \mathrm{ppm}$ polymer injection), micromodel with $0^{\circ}$ orientation angle generates the lowest incremental oil recovery even the residual oil saturation is still high in the micromodel, in which the polymer injection (1000 ppm) is not enough to improve mobility ratio and to minimize the permeability variation effect due to the layer is parallel to the mean flow direction resulting in very poor fluid flow distribution (the polymer cannot sweep oil in a low permeability zone).

6. The recovery factor resulted in micromodel with $90^{\circ}$ orientation angle was strongly affected on the selection of injection port that the recovery factor can be the highest or the lowest among the other micromodel, it proves that the fluid distribution is affected by the permeability variation near the injection port.

7. At lower injection rate $(0.05 \mathrm{cc} / \mathrm{min})$, the polymer solution has longer time to be well distributed in the micromodel, therefore the incremental oil recovery will be higher.

\section{Acknowledgements}

This paper is made as the result of our research in experimental study of polymer injection using micromodel. We thank Lembaga Penelitian dan Pengabdian Masyarakat (LPPM) UPN "Veteran" Yogyakarta for the research funding in this micromodel research and also, we thank Petroleum Engineering Department of UPN "Veteran" Yogyakarta and OGRINDO ITB for the support that has been given in this research.

\section{References}

[1] Craig, F. F. (1971) The reservoir engineering aspects of waterflooding. New York: H.L. Doherty Memorial Fund of AIME.

[2] Sheng JJ, Leonhardt B, and Azri N (2015) Status of polymer-flooding technology. J Can Pet Technol 54: Issue 02.

[3] Painter, Paul C. and Coleman, Michael M. (1997) Fundamentals of polymer science: an introductory text. Lancaster, Pa.: Technomic Pub. Co. p. 1. ISBN 1-56676-559-5. 
[4] Sheng, J. J. (2011) Modern Chemical Enhanced Oil Recovery: Theory and Practice, first edition. Amsterdam: Elsevier.

[5] Manrique, E.J., Muci, V.E., and Gurfinkel, M.E. (2007) EOR field experiences in carbonate reservoirs in the United States. SPEREE (December), 667-686.

[6] Sorbie KS (1991) Polymer-improved oil recovery, 1st ed. CRC Press, Inc, Boca Raton.

[7] Needham RB and Doe PH (1987) Polymer flooding review. J Pet Technol.

[8] D.A. Siginer and S.I. Bakhtiyarov (2001) Flow in Porous Media of Variable Permeability and Novel Effects, Journal of Applied Mechanics, Vol. 68, pp 312-319.

[9] Chatenever, Alfred, and John C. Calhoun. (1952) Visual Examinations of Fluid Behaviour in Porous Media - Part I. J Pet Technol 4: 149-156. doi: https://doi.org/10.2118/135-G.

[10] Mattax, C.C. and Kyte, J.R. (1961) Ever see a Water Flood. Oil and Gas J. 115-128.

[11] Emami Meybodi H, Kharrat R, Ghazanfari MH (2008) Effect of heterogeneity of layered reservoirs on polymer flooding: an experimental approach using 5-spot glass micromodel. Europec/ EAGE conference and exhibition, 9-12 June 2008, Rome, Italy.

[12] Herbas, J.G. G., Wegner, J., Hincapie, R.E. E., Födisch, H., Ganzer, L., Castillo, J.A. Del, and Herbert Magyezi Mugizi. (2015) Comprehensive Micromodel Study to Evaluate Polymer EOR in Unconsolidated Sand Reservoirs. Paper presented at the SPE Middle East Oil \& Gas Show and Conference, Manama, Bahrain, March 2015. doi: https://doi.org/10.2118/172669-MS.

[13] Sedaghat, M., Mohammadzadeh, O., Kord, S., and I. Chatzis. (2015) Pore-Level Experimental Investigation of ASP Flooding to Recover Heavy Oil in Fractured FiveSpot Micromodels." Paper presented at the EUROPEC 2015, Madrid, Spain, June 2015. doi: https://doi.org/10.2118/174290-MS.

[14] Kenzhekhanov S (2017) Chemical EOR process visualisation using NOA81 micromodels. Colorado School of Mines, Golden.

[15] Hosseini SJ and Foroozesh J (2018) Experimental Study of Polymer Injection Enhanced Oil Recovery in Homogeneous and Heterogeneous Porous Media Using Glass-Type Micromodels. Journal of Petroleum Exploration and Production Technology. https://doi.org/10.1007/s13202-018-0492-X.

[16] Sugar, Antonia, Serag, Maged F., Torrealba, Victor A., Buttner, Ulrich, Habuchi, Satoshi, and Hussein Hoteit. (2020) Visualization of Polymer Retention Mechanisms in Porous Media Using Microfluidics. Paper presented at the SPE Europec, Virtual, December 2020. doi: https://doi.org/10.2118/200557-MS. 